\title{
CONSUMPTION EXTERNALITIES AND DIFFUSION \\ IN PHARMACEUTICAL MARKETS: ANTIULCER DRUGS
}

\author{
Ernst R. Berndt \\ Robert S. Pindyck \\ Pierre Azoulay \\ Working Paper 7772 \\ http://www.nber.org/papers/w7772
NATIONAL BUREAU OF ECONOMIC RESEARCH 1050 Massachusetts Avenue
Cambridge, MA 02138
June 2000

The research leading to this paper was supported by the National Science Foundation through grants to both authors, and by MIT's Program on the Pharmaceutical Industry. Our thanks to Winnie Choi and Ornsiri Rungruxsirivorn for their outstanding research assistance, and to Iain Cockburn, Clint Cummins, Neil Gandal, Austan Goolsbee, Zvi Griliches, Jerry Hausman, Andrea Shepard, and seminar participants at Columbia University, MIT, Tel Aviv University, and the NBER for helpful comments. This paper was initially prepared in honor of Zvi Griliches' 20 years as Director of the NBER Productivity Program. The views expressed herein are those of the authors and not necessarily those of the National Bureau of Economic Research.

(C) 2000 by Ernst R. Berndt, Robert S. Pindyck, and Pierre Azoulay. All rights reserved. Short sections of text, not to exceed two paragraphs, may be quoted without explicit permission provided that full credit, including $\odot$ notice, is given to the source. 
Consumption Externalities and Diffusion in Pharmaceutical Markets: Antiulcer Drugs

Ernst R. Berndt, Robert S. Pindyck, and Pierre Azoulay

NBER Working Paper No. 7772

June 2000

JEL No. D12, L65, I1 1

\begin{abstract}
We examine the role of consumption externalities in the demand for pharmaceuticals at both the brand level and over a therapeutic class of drugs. These effects emerge when use of a drug by others affects its value, and/or conveys information abut efficacy and safety to patients and physicians. This can affect that rate of market diffusion for a new entrant, and can lead to herb behavior whereby a particular drug can dominate the market despite the availability of close substitutes. We use data for $\mathrm{H}_{2}$-antagonist antiulcer drugs to estimate a dynamic demand model and quantify these effects. The model has three components: an hedonic price equation that measures how the aggregate usage of a drug, as well as conventional attributes, affect brand valuation; equations relating equilibrium market shares to quality-adjusted prices and marketing levels; and diffusion equations describing the dynamic adjustment process. We find that consumption externalities influence both valuations and rates of diffusion, but that they operate at the brand and not the therapeutic class level.
\end{abstract}

Ernst R. Berndt

Sloan School of Management

E52-452

MIT

50 Memorial Drive

Cambridge, MA 02142

and NBER

eberndt@mit.edu

Pierre Azoulay

Sloan School of Management

MIT

50 Memorial Drive

Cambridge, MA 02142
Robert S. Pindyck

Sloan School of Management

E52-453

MIT

50 Memorial Drive

Cambridge, MA 02139

and NBER

rpindyck@mit.edu 


\section{Introduction}

The process by which new products embodying technological advances diffuse through markets is fascinating and exceedingly complex. In his classic study of factors affecting the diffusion of hybrid seed corn in the U.S., Griliches (1957) distinguished three components of the diffusion process: origins (supply, depending on the potential profitability of entry), ceilings (demand, the long-run equilibrium profitability differential from adopting the innovation), and slopes (the rate of approach to market saturation).

In this paper we focus on the diffusion process characterizing a set of pharmaceutical innovations $-\mathrm{H}_{2}$-antagonist antiulcer drugs, which avoid costly hospitalizations and surgeries, and also are effective in treating rather common ailments such as heartburn. We treat the origins of this innovation as predetermined and largely exogenous, since in the United States the ability to obtain exclusive rights to bring medical innovations to the market depends not only on successful research and development, but also on the vicissitudes of obtaining approval from the U.S. Patent Office ${ }^{1}$ and the U.S. Food and Drug Administration, approvals that are the outcome of lengthy stochastic administrative and regulatory proceedings. $^{2}$ Thus, within the larger context of the diffusion process, we focus our attention on demand-side phenomena involving factors that affect rates of diffusion and long-run market saturation. We consider not only the overall therapeutic class, but also particular brand-name products within the class.

Specifically, we examine consumption externalities, i.e., the ways in which the demand for a branded pharmaceutical by patients and physicians depends on the number of other patients that have taken or are taking the drug. Consumption externalities arise when the use of a drug by others influences one's perceptions about its efficacy, safety, and "acceptability," and thus affects its valuation and rate of adoption. Consumption externalities can be reputational in nature; the greater a drug's perceived efficacy and safety, the better its

\footnotetext{
${ }^{1}$ For a discussion of factors affecting the level and rate of patent approvals, see Griliches (1990).

${ }^{2}$ The pharmaceutical innovations on which we focus here were patented by private sector organizations. Griliches (1958) has argued that for hybrid corn, the ideas underlying the innovations were difficult to patent, public sector research predominated, and social rates of return to R\&D were much larger than private rates.
} 
reputation. Unlike computer software and telecommunications systems, however, where consumption externalities stem from direct external benefits, in pharmaceutical markets these externalities are largely informational in nature.

A priori, we would expect consumption externalities to exist because the widespread use of a prescription drug may convey information to physicians and patients about its safety and efficacy, and, for physicians, may imply "accepted practice" and hence greater immunity to malpractice lawsuits. ${ }^{3}$ Thus the use of a drug by others could reflect an informational externality in which physicians and patients process data on past and current usage to rationally assess a drug's efficacy and risks. For example, the fact that a drug is currently used by, say, a million patients is evidence that it is at least somewhat efficacious relative to its side effects and risks. Or, it could reflect a physician's assessment that other things equal, the probability of a malpractice suit is lower when a widely used drug is prescribed, whatever the actual efficacy and risks of the drug.

If they are strong enough, consumption externalities could lead to herd behavior, where a particular drug — not necessarily the most efficacious or safest — comes to dominate the market despite the availability of close substitutes. They also affect the rate at which a new product diffuses into the market. Even if there were no externalities affecting individuals' valuations of a product, as more people use the product, word-of-mouth communication increases, accelerating the rate at which others become aware of it. In either case, the result can be a market outcome that is inefficient. ${ }^{4}$

We distinguish between externalities that influence consumers' valuations of a drug, and

\footnotetext{
${ }^{3}$ There is also qualitative evidence of this dependence from early sociological studies of the diffusion of new drugs and medical technologies; see, e.g., Coleman, Katz, and Menzel (1966). For a more recent study of the effects of potential malpractice liability on physician behavior, see Kessler and McClellan (1996).

${ }^{4}$ This is analogous to inefficient herd behavior resulting from informational externalities in technology adoption and investment decisions. The inefficiency arises when agents rationally try to free ride on the information generated by the adoption decisions of others, as in the models of Banerjee (1992), Choi (1997), and Scharfstein and Stein (1990). For a discussion of these and related models, see Bikhchandani, Hirshleifer, and Welch (1998). Besen and Farrell (1994) provide a good overview of such effects and some of their implications for market structure and evolution. Goolsbee and Klenow (1999) present evidence of very similar spillover effects in consumers' purchases of home computers. Gandal, Kende, and Rob (2000) estimate a dynamic demand model of technology adoption for compact disc players and CD titles.
} 
those that influence the rate of diffusion in the market. ${ }^{5}$ Consumers' valuations are affected when the use of a drug by others influences its perceived efficacy and safety. One of our goals is to determine the magnitude of this effect. A second goal is to assess the importance of cumulative sales and/or market share as a determinant of the rate of product diffusion.

Pharmaceutical markets are usually bounded in terms of therapeutic classes of drugs, the members of which often are therapeutic substitutes. Hence it is also important to distinguish between consumption externalities at two levels. The first is with respect to a therapeutic class, e.g., $\mathrm{H}_{2}$-antagonist antiulcer drugs, SSRI antidepressants, or cholesterol-lowering drugs. We expect that physicians may be more willing to prescribe and patients to take a drug the more the therapeutic class of which that drug is a member has been "accepted," where "acceptance" can be measured at least in part by the number of other people that have taken drugs in that class. The second is with respect to a specific brand of drug within a therapeutic class. We might expect that physicians and patients are more willing to use Zantac (as opposed to, say, Tagamet, Axid, or Pepcid) the greater is its "acceptance," which might be measured by its market share, total sales, or cumulative sales.

Although our focus is on the demand side of pharmaceutical markets, the issues we examine have broad implications for market structure and performance. For example, the fact that consumption externalities can lead to "tipping" may give firms the incentive to compete very aggressively in the early stages of market evolution, as they struggle to win a future position with substantial market power. When the willingness of consumers to buy a new product depends on the number of other consumers who have purchased the product, sales may never take off, or, if stimulated by initially low prices, might grow very rapidly. Even with no externalities affecting consumers' valuations of a product, an initially large market share can lead to "tipping" by affecting the rate of diffusion. Suppose there are two competing products and switching costs are high. If the rate of diffusion for each product depends positively on the number of consumers already using the product, the firm with an

\footnotetext{
${ }^{5}$ The decision to utilize a drug can be made or influenced by both the patient and the physician, and we do not try to differentiate their roles in the adoption decision. We include both groups when we refer to "consumers."
} 
initial market share advantage could increase that advantage as the market saturates, and win a future near-monopoly position.

When they occur at the brand level, consumption externalities have implications for pricing, advertising, and R\&D decisions. They can create an incentive to price low initially and advertise heavily, and later provide the owner of a dominant brand the ability to raise price above those for other brands. They also affect the reward for being the first drug in a new therapeutic category. A strong brand-specific effect creates a first-mover advantage, making it worthwhile to invest heavily to accelerate the development of a new drug. Conversely, a strong therapeutic class effect can create second-mover advantages, whereby later entrants free-ride on the information and awareness generated by the pioneering brand. If this effect dominates, firms might find it optimal to arrive second on the market, if that can provide an opportunity to develop a drug with slightly better attributes (e.g., requiring less frequent dosing or having fewer side effects) than those of the first mover. ${ }^{6}$

In this paper, we focus on a particular therapeutic class, namely the $\mathrm{H}_{2}$-antagonist antiulcer drugs, which includes four competing products: Tagamet (manufactured by SmithKlineBeecham), Zantac (GlaxoWellcome), Pepcid (Merck), and Axid (Eli Lilly). ${ }^{7}$ These four drugs comprise a well-defined market because they all work in roughly the same way — they cause the stomach to produce less hydrochloric acid than it would otherwise. They differ in terms of dosing frequency, side effects, and their interactions with other drugs, but for most patients they could readily be substituted for each other. ${ }^{8}$ Our analysis covers the time pe-

\footnotetext{
${ }^{6}$ Indeed, as we will see, this appears to be the case with $\mathrm{H}_{2}$-antagonist antiulcer drugs. Zantac arrived second but with better attributes than first-mover Tagamet, and soon attained a dominant share of the market. For discussions of first-mover advantages in prescription drug markets, see Bond and Lean (1977), and Berndt, Bui, Reilly, and Urban $(1995,1997)$. For an empirical study of pricing strategies in these markets, see Lu and Comanor (1998).

${ }^{7}$ Tagamet (the chemical compound cimetidine) went off patent in May 1994, and Zantac (ranitidine) in July 1997. More recently, the market was enlarged by the introduction of Prilosec, a proton pump inhibitor, which in 1996 became the world's top-selling drug. Here we confine our attention to the period prior to Tagamet patent expiration.

${ }^{8}$ There are many other examples of well-defined pharmaceutical markets. Anti-cholesterol "statin" drugs are one, with five major products: Lipitor (Warner Lambert), Mevacor and Zocor (Merck), Pravachol (Bristol-Myers-Squibb) and Lescol (Novartis). These drugs all do much the same thing (reduce blood cholesterol levels) in much the same way, and while their side effects and interactions differ somewhat, they are all therapeutic substitutes. Sometimes pharmaceutical market boundaries are more ambiguous. Consider
} 
riod from 1977, when Tagamet was first introduced, through 1993, the year before Tagamet lost patent protection and two years before over-the-counter versions of the $\mathrm{H}_{2}$-antagonist drugs were introduced. Prilosec, a proton-pump inhibitor used to treat similar disorders, was introduced in the United States in 1989. However, until 1995 the FDA required Prilosec to carry a warning on its label concerning safety in long-term treatment, so that it was not a strong substitute for the $\mathrm{H}_{2}$-antagonist drugs.

Because the four drugs were introduced sequentially, this data set allows us to address a variety of important issues related to brand diffusion and competition. How important, for example, is the first-mover advantage resulting from an "installed base" of patients? How does that installed base affect the rate of diffusion for a new brand, as well as substitution across brands? What portion of a drug's value can be attributed to brand-level versus therapeutic class-level consumption externalities? We can also examine strategic issues specific to this industry. Zantac was introduced in the market at a higher price than Tagamet and had the disadvantage of being a "second mover," but overtook Tagamet in sales after about five years. To what extent was this due to Zantac's better attributes and substantially higher level of marketing?

Our model has three components. We first estimate an hedonic price equation that adjusts prices for quality by accounting for the price impacts of objective attributes such as the number of side effects, dosing, etc. We also include cumulative lagged sales of a brand and/or the therapeutic class as additional attribute variables. This allows us to measure the importance of a drug's past usage, as well as conventional attributes, as components of value.

We then use the quasi-residuals from this hedonic price index as a quality-adjusted price,

painkillers, of which there are many types, with varying efficacy and side-effect profiles. Examples include nonsteroidal anti-inflammatory drugs, such as aspirin, acetaminophen, ibuprofen, naproxen, and voltaren. NSAIDs have both anti-inflammatory and analgesic effects, and may cause gastro-intestinal bleeding as a side effect. Another class of painkillers is the new cyclooxygenase-2 (COX-2) inhibitors, Celebrex and Vioxx. While some types of painkillers are used more frequently than others for certain symptoms or conditions, there is considerable spillover. For example, depending on the severity of the pain, osteoarthritis might be treated with many of the painkillers mentioned above. Hence the boundaries of a "painkiller market" can be difficult to define. 
and, based on data for the last four years of our sample, estimate an equilibrium model of brand shares. During this period we can reasonably expect that all four brands have fully diffused through the market, so we can measure the equilibrium dependence of sales on relative (quality-adjusted) prices and marketing levels.

The third part of our model is a set of dynamic diffusion equations that explains the adjustment of sales to their equilibrium, or saturation, levels. These saturation levels depend on prices, advertising levels, and population, and thus change over time as these variables evolve. In these diffusion equations, the adoption of the therapeutic class, and the adoption of a particular brand of drug within that class, depends indirectly on drug attributes through the hedonic residuals, as well as on prices and marketing efforts. But rates of diffusion also depend directly on past sales of the therapeutic class and/or the particular brand, reflecting learning and word of mouth effects. Thus variables reflecting past sales can affect rates of diffusion and equilibrium market shares through multiple channels.

This modelling approach imposes structural assumptions (e.g., that the last four years of our sample represents a period of market equilibrium) as a means of identifying key parameters, and is discussed in more detail in the next section. Section 3 discusses the data and estimation methods. Estimates of the hedonic price equations are presented and discussed in Section 4, and in Sections 5 and 6 we present the results of estimating the dynamic diffusion models, first at the industry level, and then at the brand level. Section 7 presents the results of several simulation experiments, and Section 8 concludes.

\section{Modelling Pharmaceutical Demands}

Relative to other goods, modelling the demands for pharmaceutical products is complicated by the presence of consumption externalities and dynamic diffusion, both of which create hysteresis (i.e., history dependence). Specifically, the past sales of a drug can affect its current demand by directly affecting its value to consumers, and by increasing awareness of the drug's existence and thereby accelerating its rate of diffusion. Our model, which has three components, accounts for these two mechanisms, both at the therapeutic class and 
brand levels.

First, perceptions of a drug's efficacy, safety, and medical "acceptability" are essentially perceptions of its quality. Hence if the use of a drug by others affects these perceptions, it should affect the drug's quality-adjusted price. This suggests that one could estimate the perceived value of a drug's past sales or market share from an hedonic price regression that includes such a variable in addition to other product attributes. Therefore we begin by estimating an hedonic price equation for the therapeutic category, using an (unbalanced) panel of prices and attributes for the four $\mathrm{H}_{2}$-antagonist drugs. Included among those attributes are measures of the numbers of patients that are taking the drug or have taken it during some previous time interval. ${ }^{9}$ Thus we can test whether variables that reflect the acceptance of a drug help to explain prices as expected, and we can estimate their relative contribution to perceived value. Also, we employ the quasi-residuals of this hedonic price regression as a quality-adjusted price in the other two components of our model.

Second, using the hedonic quasi-residuals, along with data on brand advertising, we estimate equations for the equilibrium market shares of the four brands. To do this, we use data only for the last $41 / 2$ years of our sample, a period for which the market was mature so that adjustment to equilibrium was largely complete. Because the number of drugs on the market was changing during the years prior to this equilibrium period, we use a multinomial logit model. This restricts the equilibrium cross-price elasticities to be the same for drugs with equal shares, but yields partial (i.e., subject to a constant total industry demand) own-price and advertising elasticities that depend on market shares but not on the number of drugs in the market. Using these equilibrium share equations, we calculate fitted equilibrium brand shares for the entire sample period. For example, we calculate what the Tagamet and Zantac shares would have been in, say, 1985, when these were the only two drugs on the market, but were not yet in equilibrium.

As explained earlier, past sales can influence the rate of product diffusion through word

\footnotetext{
${ }^{9}$ Gandal (1994) and Brynjolfsson and Kemerer (1995) employed such an approach to estimate the magnitude and value of network effects in spreadsheet software programs. Berndt, Cockburn, and Griliches (1996), Cockburn and Anis (1998), and Suslow (1996) have estimated hedonic price indexes of pharmaceutical products, but did not test for the presence of consumption externalities.
} 
of mouth and related communication channels. When more people have used a drug, there will be a greater knowledge of its existence and attributes, and thus a more rapid response by physicians and patients who are potential adopters. If past sales are indeed a product attribute that affects the quality-adjusted price, there will be indirect effects on the rate of diffusion, and on equilibrium sales, through price. In particular, a greater acceptance of a drug will imply that, ceteris paribus, the quality-adjusted price is lower, which can make the level of sales at which the market ultimately saturates higher, and also make the rate of new product trials higher. These indirect effects are simply implications of a negative price elasticity of demand.

Thus the third step is to estimate a set of dynamic diffusion equations for the four individual brands. These equations explain changes in the sales of a particular brand in terms of adjustment to that brand's equilibrium share of an industry saturation level (which is estimated), where the adjustment is partly due to the influence of an "installed base" of patients that are using or have used the drug, and partly independent of that base. Furthermore, the installed base is measured with respect to the entire therapeutic category and with respect to the individual brand. In this way we can estimate the relative importance of category-specific versus brand-specific spillover effects on the rate of diffusion.

This three-step approach has the distinct disadvantage that it imposes strong structural assumptions - most notably that we can identify a period of market equilibrium. An alternative approach would be to substitute functional expressions for the brands' equilibrium shares directly into the diffusion equations, and then estimate those equations over the entire sample. We have examined that approach, but found that it is not possible to identify key parameters. By imposing identifying assumptions, our three-step approach has a number of advantages. First, it lets us measure the importance of spillover effects as a component of perceived value, and in terms of its influence on the rate of product diffusion. Second, we can model the structure of interbrand competition in a parsimonious way (namely, through the use of a logit model), without the usual problem of having to sacrifice the dynamic aspects of demand. Third, the three parts of the model each provide information regarding a different aspect of demand, and by simulating the model as a whole, we can address questions raised 
in the Introduction, such as the extent to which Zantac's performance can be attributed to its better attributes and higher rate of advertising.

\subsection{Hedonic Price Equation}

In order to model equilibrium brand shares, as well as the diffusion process, we require prices that take into account quality variations across products and over time. We therefore estimate hedonic price equations that relate the price of product $i$ at time $t, p_{i t}$, to a set of measured quality characteristics, $C_{i t}$, a set of time dummy variables, $D_{t}$, and two measures of product acceptance: the depreciated stock of cumulative patient days of therapy of brand $i$ to time $t, \mathrm{XS}_{i t}$, and the corresponding depreciated stock for the therapeutic class as a whole, $\mathrm{XS}_{t}$.

The theoretical literature provides little guidance on the appropriate functional form for estimating quality adjusted prices. ${ }^{10}$ Following numerous others, we employ both linear and semi-log specifications. For the linear form, the hedonic price equation is

$$
p_{i t}=C_{i t}^{\prime} \beta+D_{t}^{\prime} \gamma+\omega_{1} \mathrm{XS}_{i, t-1}+\omega_{2} \mathrm{XS}_{t-1}+\eta_{i t}
$$

where $\beta, \gamma$, and $\omega$ contain parameters to be estimated, and $\eta$ is a stochastic disturbance term. The depreciated stock of cumulative patient days of therapy to time $t$ is computed as

$$
\mathrm{XS}_{i t}=\sum_{\tau=0}^{t}(1-\delta)^{\tau} X_{i, t-\tau}
$$

and similarly for $\mathrm{XS}_{t}$, but using $X_{t}=\sum_{i} X_{i t}$. Here, $\delta$ is a monthly rate of depreciation and $X_{i, t-\tau}$ is sales of patient days of therapy of drug $i$ in month $t-\tau$. As discussed in Section 6 , we set $\delta=.04$.

To obtain measures of quality-adjusted prices, we re-arrange eqn. (1) and compute a quasi-residual as follows:

$$
P_{i t}=p_{i t}-C_{i t}^{\prime} \hat{\beta}-\hat{\omega}_{1} \mathrm{XS}_{i, t-1}-\hat{\omega}_{2} \mathrm{XS}_{t-1}
$$

where $\hat{\beta}$ and $\hat{\omega}$ are parameter estimates. Notice that variations in $P_{i t}$ over time and across products net out the impacts of quality differences, including valuations of past sales as

\footnotetext{
${ }^{10}$ For a discussion, see Chapter 4 in Berndt (1991) and the references cited therein.
} 
measured by the depreciated stock of cumulative patient days of therapy, among drugs and over time.

\subsection{Equilibrium Shares}

We use a simple multinomial logit model to describe equilibrium brand shares. Denoting the quantity share of brand $i$ at time $t$ by $s_{i t}^{*}$, equilibrium shares are given by:

$$
\log \left(\frac{s_{i t}^{*}}{s_{T, t}^{*}}\right)=a_{i 0}+a_{1}\left(P_{i t}-P_{T, t}\right)+a_{2}\left(\operatorname{MINSTK}_{i t}-\operatorname{MINSTK}_{T, t}\right)+\epsilon_{i t},
$$

where $i=\mathrm{Z}$ (Zantac), A (Axid), and P (Pepcid), $s_{T, t}^{*}$ is the equilibrium share of Tagamet, $P_{i t}$ is the quality-adjusted price from eqn. (3), and MINSTK $i t$ is the depreciated stock of detailing minutes, our measure of marketing. Variation in patient and physician "tastes" occurs through the error term, $\epsilon_{i t}$.

This parsimonious model imposes restrictions on equilibrium demands — for any two drugs, cross-price elasticities with respect to a third drug can differ only to the extent that the first two drugs have different market shares. The restrictive substitution patterns generated by logit errors in demand models are well documented; see, e.g., McFadden (1984) and Berry (1994). In our case, however, these restrictions are less problematic. First, there are only four different products in the market. Second, the products are all close substitutes. The difference between any two $\mathrm{H}_{2}$ drugs is far smaller than the difference between, say, a Ford Escort and a Lexus, so there is less need to use the more complex approach of Berry, Levinsohn and Pakes (1995). Also, note that this demand model does not include an outside good. The reason is that our dynamic diffusion models explain the adjustment to an endogenous saturation level $X_{t}^{*}$ (see below), and thus account for consumers' outside treatment options.

\subsection{Saturation Levels}

The model described above provides estimates of equilibrium shares. These shares can in turn be used to determine saturation levels for each brand, i.e., the level of sales that a brand would reach once in equilibrium. Note that these saturation levels are not constant - they 
depend on the equilibrium market shares, which will change as relative prices and advertising levels change, and they also depend on the saturation level for sales of the overall therapeutic category, which will also change as the population grows and as the average industry price changes.

We denote the industry saturation level by $X_{t}^{*}$, and we model it as a function of the average industry quality-adjusted price $\bar{P}_{t}$, the total stock of depreciated detailing minutes for the industry MINSTKTOT, , and population $\mathrm{POP}_{t}$. In its linear form, it is given by

$$
X_{t}^{*}=\left(b_{0}+b_{1} \bar{P}_{t}+b_{3} \mathrm{MINSTKTOT}_{t}\right) \mathrm{POP}_{t} e^{\beta t}
$$

and in log form by

$$
\log X_{t}^{*}=b_{0}+b_{1} \log \bar{P}_{t}+b_{2} \log \mathrm{POP}_{t}+b_{3} \log \mathrm{MINSTKTOT}_{t}
$$

Given the equilibrium shares $s_{i t}^{*}$ and this industry saturation level, the saturation level for each brand is just $X_{i t}^{*}=s_{i t}^{*} X_{t}^{*}$.

\subsection{Dynamic Diffusion Equations}

The third part of our model is a set of equations that describes the evolution of demand over time. We use a model of product diffusion at the brand level, where the sales of each brand approach a saturation level equal to the brand's equilibrium market share times the saturation level for total sales of the therapeutic category. The specification of our diffusion model is not derived from a formal dynamic optimization model, in part because of difficulties of dealing with the impact of moral hazard (due to insurance) and principal-agent issues (the physician-patient relationship). Nonetheless, models of this kind have been widely used in marketing studies of new product diffusion, and allow us to distinguish among alternative sources of sales growth. ${ }^{11}$ Two basic versions of this equation have permeated the literature. The first is the generalized logistic equation:

$$
\frac{d X_{t}}{d t}=\alpha\left(X_{t}^{*}-X_{t}\right)+\beta X_{t}\left(X_{t}^{*}-X_{t}\right)
$$

and the second is the generalized Gompertz equation:

$$
\frac{d X_{t}}{d t}=\alpha\left(\log X_{t}^{*}-\log X_{t}\right)+\beta X_{t}\left(\log X_{t}^{*}-\log X_{t}\right)
$$

\footnotetext{
${ }^{11}$ Bass (1969) developed one of the first of these models. For an overview of diffusion models of this type and their application, see Mahajan and Muller (1979) and Mahajan, Muller, and Bass (1990).
} 
The first term on the right-hand side of eqns. (7) and (8) represents sales growth (towards the saturation level) that is independent of usage of the drug by others. (It may be due purely to advertising, a willingness by physicians to experiment with a new drug, etc.) The second term in these equations represents sales growth that is due to the influence of current sales. As discussed above, the saturation level $X_{t}^{*}$ can depend on prices, demographics (such as changing disease prevalence due to variations over time in the age distribution of the population), and "events" such as the approval of a drug for treatment of some condition, and hence will vary over time.

If $\alpha=0$ and $X_{t}^{*}$ is constant, the solutions to both of these equations are S-shaped "saturation" curves, where sales begin increasing slowly, then accelerate, and finally level out as $X_{t}$ approaches $X_{t}^{*}$. If $\alpha>0$, sales can accelerate faster early on, because sales growth is not dependent solely on the current level of sales. If $X_{t}^{*}$ is not constant, i.e., the saturation level is varying over time (perhaps in response to changing prices, medical information, or demographics), sales pursue a moving target.

\subsubsection{Diffusion of a Therapeutic Class}

Although our focus is on the diffusion of individual brands, we will first specify and estimate a model describing the diffusion of the entire therapeutic category. This is simpler, and will allow us to obtain initial estimates of long-run own price elasticities for the therapeutic categories. We work with the following discrete-time versions of the continuous-time diffusion processes above:

$$
X_{t}-X_{t-n}=\left(X_{t}^{*}-X_{t-n}\right)\left(c_{0}+\sum_{k=2}^{12} \theta_{k} m_{k t}+d_{0} \mathrm{XS}_{t-n}\right)
$$

and

$$
X_{t}-X_{t-n}=\left(\log X_{t}^{*}-\log X_{t-n}\right)\left(c_{0}+\sum_{k=2}^{12} \theta_{k} m_{k t}+d_{0} \log \mathrm{XS}_{t-n}\right)
$$

where $\mathrm{XS}_{t}$ is depreciated cumulative sales for the therapeutic category, and the lag $n$ is one, three, or six months. Note that in contrast to eqns. (7) and (8), sales growth is influenced not by current sales but instead by the depreciated stock of past sales. 
Equations (9) and (10) are estimated after substituting in eqns. (5) for $X_{t}^{*}$ and (6) for $\log X_{t}^{*}$ respectively. Estimates of $d_{0}$ measure the importance of consumption externalities in driving the rate of market saturation at the level of the therapeutic class.

\subsubsection{Brand-Level Diffusion}

Here our main concern is with the process of diffusion for the individual brands. We adapt the diffusion model described above by noting that the potential saturation level for brand $i$ is given by $s_{i t}^{*} X_{t}^{*}$, where $s_{i t}^{*}$ is the equilibrium share of brand $i$ (which in turn is a function of relative prices and advertising levels). In describing the diffusion process, we want to allow for consumption externalities to occur at both the brand and the therapeutic category levels. Hence we estimate the following two alternative discrete-time diffusion equations:

$$
X_{i t}-X_{i, t-n}=\left[\log \left(\hat{s}_{i t}^{*} X_{t}^{*}\right)-\log X_{i, t-n}\right] \cdot\left[C_{i}+\sum_{k=2}^{12} \theta_{k} m_{k t}+d_{0} \mathrm{XS}_{t-n}+d_{1} \mathrm{XS}_{i, t-n}\right]
$$

and

$$
X_{i t}-X_{i, t-n}=\left[\log \left(\hat{s}_{i t}^{*} X_{t}^{*}\right)-\log X_{i, t-n}\right] \cdot\left[C_{i}+\sum_{k=2}^{12} \theta_{k} m_{k t}+d_{0} \log \mathrm{XS}_{t-n}+d_{1} \log \mathrm{XS}_{i, t-n}\right]
$$

Note that the parameters $d_{0}$ and $d_{1}$ measure the effects of industry-level and brandspecific spillovers, respectively, on the rate of diffusion of each brand. When we estimate these equations, we use both the in-sample and out-of-sample fitted values of the equilibrium shares, $\hat{s}_{i t}^{*}$. The industry saturation level, $X_{t}^{*}$, is endogenous, and is given by eqn. (6).

\section{Measurement and Data}

The data employed here are described in considerable detail in the Data Appendix of Berndt, Bui, Reiley, and Urban (1997). To aggregate over the various strengths and presentational formulations for each $\mathrm{H}_{2}$-antagonist, we divide monthly sales in total milligrams of active ingredient by the recommended daily dosage, in milligrams, for duodenal ulcer treatment. This yields patient days of therapy $X_{i t}$, expressed in millions. By 1993, monthly sales approximated 120 million patient days of therapy, which is roughly equivalent to 4 million patients. Total revenue from sales of $\operatorname{drug} i$ in month $t$ is divided by $X_{i t}$, thereby yielding 
nominal price per day of patient therapy. We deflate this nominal price by the Producer Price Index for finished goods $(1982=1.00)$ to obtain the real price per day of therapy for drug $i$, expressed in constant 1982 dollars. In 1993, the average real price of an $\mathrm{H}_{2}$ patient day of therapy was about $\$ 1.50$. Both price and quantity measures refer to sales from wholesalers to retail drug stores, as computed by IMS America.

Marketing efforts are important in the $\mathrm{H}_{2}$-antagonist therapeutic class. Using data from IMS America, we employ as our measure of marketing the number of minutes that physicians in the United States were "detailed" by pharmaceutical sales representatives. In the 1990s, monthly minutes of detailing ranged from about 40,000 to 250,000, varying considerably by product and over time. We construct a cumulative depreciated stock of detailing minutes, MINSTK $_{i t}$, for each brand. This stock is expressed in millions of minutes, and is computed analogously to eqn. (2), with $\delta=.05$. This value for $\delta$ is chosen for two reasons. First, it is approximately the rate estimated in Berndt et al. (1997) and King (1997). Second, we performed a grid search for $\delta$ by repeatedly estimating the equilibrium share equations using generalized method of moments estimation (GMM). The GMM objective function is quite flat over values of $\delta$ between .02 and .08, and has two local minima; the value of .05 lies midway between those minima.

When computing the quality-adjusted average price for the $\mathrm{H}_{2}$ class, $\bar{P}_{t}$, we weight each of the products on the market at that time by the average patient-day share during the period. These average shares are computed separately for epochs when there were two, three, and four $\mathrm{H}_{2}$ products on the market. We also compute a total level of advertising for the therapeutic class, MINSTKTOT, , by summing MINSTK $_{i t}$ over all four products.

For quality characteristics of each drug, a number of measures are available. DOSAGE is the number of tablets per day required to attain the recommended daily consumption of the active ingredient. When Zantac was introduced in 1983, it offered a twice-a-day dosage, in contrast to the incumbent Tagamet's four-times-a-day version. Lower DOSAGE is generally thought to indicate greater quality, for patient compliance is typically improved with lower daily DOSAGE. Note that the DOSAGE variable changes over time as manufacturers obtained FDA approval to market more convenient dosages, which ultimately became available 
in once-a-day formulations for all four brands.

$\mathrm{H}_{2}$-antagonist drugs have also competed on the basis of differing medical conditions for which the product has obtained FDA marketing approval; these are called approved indications. Zantac was the first $\mathrm{H}_{2}$-antagonist to obtain approval for the GERD (gastroesophageal reflux disease) indication, a relatively common ailment whose symptoms vary from mild heartburn to very intense pain. Although all four $\mathrm{H}_{2}$-antagonists had obtained approval at product launch date for active duodenal ulcer treatment, FDA approval times varied for active gastric ulcer treatment, duodenal ulcer maintenance treatment, and stress ulcer prophylaxis. We compute the SUMATT variable as the sum of the indications, other than GERD and active duodenal ulcer treatment, for which the drug had obtained FDA approval.

Finally, an important quality attribute of prescription drugs is the extent to which they might interact adversely with other medications. This is particularly important for the elderly population, who often take several concomitant medications. The bodily absorption of Tagamet, the first entrant, involved a metabolic process that adversely affected a number of other medications, some of them used for treatment of common conditions such as those involving blood coagulation, anxiety, and asthma. For each of the four $\mathrm{H}_{2}$-antagonists we construct a variable named INTER that sums up the number of major drugs with which that $\mathrm{H}_{2}$-antagonist had adverse interactions, as reported in annual editions of Physicians' Desk Reference. By the end of our sample, in late 1993, Tagamet had registered ten adverse interactions, while Zantac, Pepcid, and Axid had either zero or one.

The construction of other variables is as follows. TIME is a time counter taking on the value of one in the first month of the sample time period, August 1977, and then proceeding with the passage of time. The U.S. population data was taken from the U.S. Census Bureau web site, www.census.gov, and is expressed in millions.

Growth of $\mathrm{H}_{2}$-antagonist industry sales was remarkably steady over the 1977-93 time period, averaging about 15 percent per year. Monthly quantity data for the four $\mathrm{H}_{2}$ drugs are given in Figure 1. Although Tagamet was the pioneer and only $\mathrm{H}_{2}$-antagonist drug from 1977 until Zantac entered in July 1983, Zantac captured a significant market share very 
rapidly - almost 25 percent within the first year. Total industry sales continued to increase following the entry of Zantac, but soon after Zantac's entry sales of Tagamet began to fall, peaking at about 46 million patient days in April 1984. Tagamet's share continued to decline when Pepcid entered in October 1986, but Pepcid was less successful than Zantac; Pepcid's market share one year after its entry was only about 8 percent. By January 1988, Zantac sales overtook those of Tagamet, and at about the same time (April 1988), Axid entered. As the fourth entrant, however, Axid faced considerable competition, and one year after its launch, its market share was only about 4 percent. By the end of our sample in May 1993, Zantac held about 55 percent of the quantity market share, Tagamet 21 percent, Pepcid 15 percent, and Axid 9 percent.

Figure 2 shows market shares for the four drugs over the entire sample period. Note that Tagamet's market share dropped to about 20 percent by the end of the period, and the combined shares of Axid and Pepcid stabilized at just over 20 percent.

In terms of real (quality-unadjusted) prices, after original entry until it faced competition from Zantac, Tagamet gradually decreased its real price from about $\$ 1$ to $\$ 0.80$ per day. As shown in Figure 3, not only did Zantac enter with a considerable price premium over Tagamet, but thereafter prices of both Zantac and Tagamet rose with time, although Tagamet's price increased more rapidly. By the end of the sample, the Zantac price premium had narrowed from about 56 percent to about 25 percent. Prices of the third and fourth entrants, Pepcid and Axid, generally fell in between those of Zantac and Tagamet.

Finally, Figure 4 shows the depreciated stock of detailing minutes, MINSTK $i t$, for each brand. (The stocks are computed using a monthly depreciation rate of 5 percent.) Note that the advertising stocks for all four brands steadily rose during most of the time that they were on the market, but Tagamet's fell during the last two years of our sample, perhaps in expectation of the imminent loss of patent protection in May 1994.

The data employed in the empirical analysis of the hedonic and brand diffusion models comprise an unbalanced panel, while those for the equilibrium share equations constitute a balanced panel. We estimate the parameters of the hedonic price eqn. (1) by ordinary least squares, and compute heteroscedasticity-consistent and $\operatorname{ARMA}(2,2)$ serial correlation- 
consistent standard errors. We estimate the logit equations for the equilibrium brand shares three ways - as a seemingly unrelated regression (SUR), by three-stage least squares (3SLS), and by generalized method of moments (GMM). The diffusion model for the entire $\mathrm{H}_{2^{-}}$ antagonist class is nonlinear in the parameters, so we estimate it using nonlinear least squares. Since the share weights of the individual drugs are constant arithmetic means within each epoch, we treat the industry average price variable as exogenous.

We also estimate the brand-specific diffusion model of eqn. (11) by nonlinear least squares (NLS). For each brand $i$, we form the vectors $X_{i}$ with components that begin at different time periods for each $i$ (e.g., August 1977 for Tagamet, July 1983 for Zantac, etc.). We stack the $X_{i}$ 's into a vector $X$ which comprises our unbalanced panel.

Table 1 shows summary statistics for the variables used in the model. Part A includes aggregate industry variables, and Parts $\mathrm{B}$ to $\mathrm{E}$ include brand-specific variables. Part F shows summary statistics for each brand's market share, price, and marketing for the last 53 months of our sample (the "equilibrium" time period).

\section{Hedonic Price Equations}

Table 2 presents the results of estimating linear and semi-log hedonic price equations for our unbalanced panel of four drugs. We first estimate the hedonic price equation by OLS. There may be serial correlation in the residuals, but we have no basis for making assumptions about its structure. We therefore re-estimate the model using GMM, with an instrument set composed of all of the right hand side variables. The point estimates do not change, but the $t$-statistics are thus robust to the presence of heteroscedasticity and $\operatorname{ARMA}(2,2)$ serial correlation in the residuals. All of the regressions include annual and quarterly time dummies (not shown). These dummies are highly significant, and show that real, qualityadjusted prices fell from 1977 through 1981, and then rose gradually through 1993.

We work with four basic attribute variables, whose construction and interpretation was discussed in Section 3: GERD, SUMATT, INTER, and DOSAGE. As can be seen from the table, GERD, INTER, and DOSAGE are all highly significant and have the expected signs; 
SUMATT is usually insignificant, and has the wrong sign. ${ }^{12}$

Each equation also has one or two variables that are intended to identify and measure the effects of past sales at the brand-specific and at the therapeutic category levels. The first variable, $\mathrm{XS}_{i, t-1}$, is the depreciated stock of past sales of brand $i$, calculated using a monthly depreciation rate of 4 percent. The second variable, $\mathrm{XS}_{t-1}$ at the therapeutic-category level, is the corresponding depreciated stock of past sales for the therapeutic-category. As can be seen from Table 2, the brand-specific variable $\mathrm{XS}_{i, t-1}$ is always positive and highly significant in both the linear and semi-log versions. The depreciated stock of sales at the therapeutic category level, $\mathrm{XS}_{t-1}$, however, is insignificant. We infer from this that the use of a drug by others affects its valuation, and that this effect operates at the brand rather than the therapeutic class level. ${ }^{13}$

To obtain some idea of the magnitude of this network effect, consider column (1) in part A of Table 1, where the coefficient on $\mathrm{XS}_{i, t-1}$ is about .00018. Just prior to Zantac's introduction in August 1983, Tagamet had a depreciated stock of past sales of 786 million patient days. Had this figure been about 200 million (25 percent) less, the contribution of past sales to the value of Tagamet would have been reduced by about $\$ 0.036$ (i.e., $200 \times .00018$ ), or about 5 percent of its approximately 75 cents price at that time. This implies a brandspecific valuation elasticity of $.2(.05 / .25)$, which is positive but modest. The semi-log hedonic equation yields even smaller elasticities. In all of the calculations that follow, we use Model (1) of Table 2, i.e., the linear hedonic equation.

Figure 5 shows quality-adjusted real prices for the four drugs. The sharp movements in these quality-adjusted prices are largely due to discrete changes in the drugs' attributes. For example, increases in the quality-adjusted price of Tagamet during 1980-82 are due to new information concerning additional interactions with other drugs that reduced its

\footnotetext{
${ }^{12}$ This is not surprising in view of the fact that much prescribing is "off-label," permitted but not formally approved by the FDA.

${ }^{13}$ To explore possible strategic pricing, we also ran regressions adding as a regressor the number of firms competing in the market that month, initially as a single count variable, and then as three dummy variables for the duopoly, three-firm, and four-firm epochs. The parameter estimates on these variables were always insignificant, and often of the wrong sign.
} 
effective quality. The sharp drops in the price of Tagamet in January 1985 and January 1987 are due to a change in dosing from four to two daily doses, and then two to one daily dose, respectively. Zantac's quality-adjusted price also dropped in January 1987 because its dosing dropped from two to one daily dose. Pepcid's quality-adjusted price dropped in December 1991 when it received approval for treatment of GERD.

Note that at the time of Zantac's entry in 1983, its quality-adjusted price was close to that of Tagamet. This can help us understand the pricing of Zantac. Ignoring quality differentials, Zantac was priced higher than Tagamet by about 61 cents (in 1982 dollars). One might argue that Zantac entered the market at a higher price to signal higher quality. The drug indeed had quality advantages over Tagamet, in particular fewer interactions and less frequent dosing. However, it also had a disadvantage insofar as Tagamet's installed base gave Tagamet a perceived value premium. Our hedonic equation implies that Zantac had a 72 cents advantage from its better dosing and interaction profile, and a 12 cents disadvantage from the consumption externality, implying a net price premium of only 1 cent.

\section{$5 \quad$ Equilibrium Share Equations}

Using the hedonic price equation (1) from Table 2, we construct quasi-residuals that represent quality-adjusted prices for each brand. With these quasi-residuals, along with the depreciated stock of detailing minutes for each brand, we estimate a multinomial logit model using the last 53 months of data for our sample. During this time period, all four brands are well established, and information regarding their efficacy and side-effects is well known. Thus we believe that it is reasonable to impose the identifying assumption that the market is in equilibrium during this period, so that any changes in market shares are due to changes in prices and marketing efforts.

Because price and marketing levels are likely to be endogenous, we need a set of instrumental variables for consistent estimation. We use the following set of instruments: the log of the wage rate in the pharmaceutical industry and the PPI for intermediate goods (both of which vary across time but not across firms); the cumulative stocks of detailing minutes for 
each of the four firms on all their other products (calculated the same way as MINSTK $_{i t}$ ), and quality-adjusted prices for each of the firms for $\mathrm{H}_{2}$-antagonist drugs sold to hospitals ${ }^{14}$ (which vary over time and across firms).

Estimation results for this model are given in Table 3. Columns (1) and (2) show results for seemingly unrelated regression and three-stage least squares, respectively. In model (2), a Hausman specification test fails to reject exogeneity of price and advertising; the test statistic is $6.486(\mathrm{p}=.090)$. Our preferred model is in column $(3)$, estimated by GMM. The $t$-statistics reported for this model are from heteroscedasticity-consistent and ARMA(1,1) serial-correlation-consistent standard errors. The $J$-statistic for the test of the overidentifying restrictions is 16.618; with 10 degrees of freedom (five instruments, including the constant, times three equations, minus five parameters), this has a p-value of .093.

Table 3 also presents price and detailing elasticities computed at the point of means for the 1989-1993 sample period. Focusing on column (3), note that the own-price elasticities are in the range of -0.3 to about -0.6 . These elasticities are based on holding the total quantity of $\mathrm{H}_{2}$-antagonist drugs constant when the price of a single drug changes, i.e., they only reflect substitution within the therapeutic category. The total own-price elasticities will be somewhat larger in magnitude. The estimated detailing elasticities for each brand are close to unity, which might seem large. After launch ramp-up, the advertising-to-sales ratio for these drugs is on the order of 15 to 20 percent. Thus even with own-price elasticities as high as 1 , the advertising elasticity should be on the order of about 0.2 if the marginal cost of detailing were constant. (Detailing accounted for about 80 percent of total pharmaceutical advertising.) There is anecdotal evidence, however, that the marginal cost of detailing rises sharply, and is much higher than the average cost. (It becomes increasingly difficult for detailers to get additional minutes of physicians' time.) This is consistent with our large elasticity estimates.

\footnotetext{
${ }^{14}$ The hospital and drugstore segments can plausibly be considered independent. Hospitals administer these drugs intravenously to emergency room patients in order to reduce acid secretion induced by severe trauma. On the other hand, drugstores sell oral preparations to outpatients suffering from a wide range of ulcer-related and chronic conditions. Since both markets experience common manufacturing cost shocks, hospital price changes are likely to be uncorrelated with unobserved determinants of drugstore demand.
} 
As can be seen from Table 3, our elasticity estimates are quite robust to the choice of estimation method. Although not shown in the table, both the price and detailing elasticities are also robust to the monthly depreciation rates used to compute the stock of detailing minutes and the stock of past sales. (We experimented with depreciation rates between 2 percent and 8 percent, and 3 percent and 5 percent, for detailing minutes and past sales, respectively, with very little change in the parameter estimates or the optimized value of the GMM objective function.)

Using model (3) from Table 3, we construct fitted values of equilibrium shares for the four drugs. By "equilibrium shares," we mean the shares which each of these drugs would have had at any particular point in time had the market already reached equilibrium at that point in time. For months prior to 1989, we generate out-of-sample backcasts of the equilibrium shares. For example, let $k$ denote the number of drugs competing in the market at a point in time. When $k=4$,we can write the fitted shares from model (3) in Table 3 as:

$$
\hat{s}_{i t}^{*}(4)=\frac{\exp \left(\delta_{i t}\right)}{1+\sum_{j} \exp \left(\delta_{j t}\right)}
$$

where $\delta_{i t}=\hat{a}_{i 0}+\hat{a}_{1}\left(P_{i t}-P_{T, t}\right)+\hat{a}_{2}\left(\operatorname{MINSTK}_{i t}-\operatorname{MINSTK}_{T, t}\right)$, and the subscript $T$ denotes Tagamet. When $k<4, \hat{s}_{i t}^{*}(k)$, the equilibrium share of drug $i$, can be computed as:

$$
\hat{s}_{i t}^{*}(k)=\frac{\exp \left(\delta_{i t}\right)}{1+\sum_{j} \exp \left(\delta_{j t}\right)} .
$$

\section{Diffusion Equations}

The third component of our model is a set of equations describing the diffusion of the various brands as they approach their equilibrium levels. Although our focus is on individual brand diffusion, we begin with models describing the diffusion of the entire therapeutic class. We

estimate modified logistic and Gompertz equations, using the hedonic price quasi-residuals constructed and equilibrium shares as described above.

\subsection{Diffusion at the Industry Level}

We estimate eqns. (9) and (10) using industry-level data. Note that the industry saturation level, $X_{t}^{*}$, is endogenous, and is given by eqn. (5) for eqn. (9) and by eqn. (6) for eqn. (10), 
in linear and $\log$ forms, respectively.

These equations explain the change in the level of industry sales. At issue is how large a time interval should be represented by this change. In principle, we can use our monthly data to estimate a model describing monthly changes in sales. We have done this, and the results are shown in Table 4A. However, there are issues as to whether the accounting of sales in the data is free of lags, and there is high-frequency noise in the data due to ordering and stocking decisions by drugstores. Thus we also experimented with three-month and sixmonth changes in sales. These results are shown in Tables $4 \mathrm{~B}$ and $4 \mathrm{C}$, respectively. Finally, we used two alternative variables to capture the effects of consumption externalities - the stock of depreciated past sales, $\mathrm{XS}_{t}$, and the log of this stock.

The results include estimates of the own-price elasticity of demand at the industry level. In models (2) and (4) of Table $4 \mathrm{~B}$, this elasticity is given by the estimated value of the coefficient $b_{1}$, and ranges from -0.17 to about -0.65 . These estimates are reasonable given that most patients do not pay for these drugs at the margin, and the cost of alternative treatments (such as surgery) are far greater. In models (1) and (3), the long-run price elasticities of demand are not constant, and so we compute them at the point of means. For the entire 1977-1993 sample period, these long-run price elasticities are in the range of -0.83 to about -0.94 . (This elasticity is found by setting $\Delta X_{t}=0$, i.e., from the parameters of the equation for the saturation level, $X_{t}^{*}$.)

Observe that in all of these models, the estimated coefficient $d_{0}$ is positive and significant. This coefficient (as opposed to the constant term, $C_{0}$ and the coefficient on the seasonal dummies) represents the component of sales growth (towards the saturation level) that is related to previous sales. Thus, we find that past sales indeed affect the continued growth of sales. Of course we cannot determine from this whether the consumption externality is operating at the industry- and/or brand-specific levels since the equation is fitted using aggregate industry sales. Also, note that this externality relates to the rate of diffusion, and is distinct from the brand-specific effect on valuation that we observed in our hedonic price equations.

To assess the ability of these equations to replicate the evolution of industry sales, we 
performed dynamic simulations, in which quality-adjusted price, population, and total industry detailing minutes were all exogenous, and the sales level, $X_{t}$, is solved recursively from month to month. Figure 7 plots the results of this dynamic simulation for model (2) in Table 4B. It shows the actual level of sales in millions of patients (the fluctuating line), the simulated saturation level (the relatively smooth curve), and the simulated level of sales. Note that the model predicts saturation to occur in about three years, whereas actual sales took about four years to saturate (assuming our estimates of the saturation level are correct). Simulations of the other models in Tables $4 \mathrm{~A}$ through $4 \mathrm{C}$ typically resulted in similar rapid rates of saturation. Simulation diagnostics are displayed in column (1) of Table 6.

As can be seen from Figure 7, the estimated saturation level $X_{t}^{*}$ grows four-fold from 1977 to 1993, i.e., more than 9 percent per year, much faster than the underlying population growth rate. What might account for this? One possibility is that the perceived long-term safety of using an $\mathrm{H}_{2}$-antagonist drug depends not only on how many people have taken the drug, but also on how long the drug has been in use, particularly for patients with chronic conditions requiring maintenance therapy. Hence longer usage increases the perceived safety for a large potential population, and thereby increases the saturation level. ${ }^{15}$

\subsection{Diffusion at the Brand Level}

Tables 5A, 5B, and 5C show the results of estimating the modified Gompertz model given by eqns. (11) and (6) for the diffusion of the four individual brands. Once again, we estimate models with one-month, three-month, and six-month differences in the sales of each brand. In addition, we estimate models in which the depreciated stock of past sales (of the brand and of the total therapeutic category) appear in linear and in logarithmic form. We first estimate these models making the industry saturation level, $X_{t}^{*}$, endogenous. We then reestimate the models with $X_{t}^{*}$ exogenous, using the fitted values from Tables $4 \mathrm{~A}$ through $4 \mathrm{C}$. In each case the models are estimated by NLS, combining the data for the four brands to form an

\footnotetext{
${ }^{15}$ Discussions with industry personnel also suggest that disorders treated by $\mathrm{H}_{2}$-antagonists have a greater prevalence in individuals over age 45 , an age category that has been increasing more rapidly than the overall population.
} 
unbalanced panel.

Note that as in the industry-level diffusion models discussed above, individual brand prices affect the average quality-adjusted price for the therapeutic category, $\bar{P}_{t}$, which in turn affects the saturation level. In addition, relative prices affect the saturation level for the brand through its equilibrium share. Finally, the long-run own-price elasticity for the therapeutic category is given by the estimated coefficient, $b_{1}$. This elasticity is on the order of -0.3 to -0.9 . The total own-price elasticity for each individual brand is given by:

$$
E_{i}^{P}=\frac{\partial \log s_{i}^{*}}{\partial \log P_{i}}+b_{1} \bar{s}_{i 4}=a_{1}\left(1-s_{i}^{*}\right) P_{i}+b_{1} \bar{s}_{i 4}
$$

Likewise, the total detailing elasticity for each individual brand is given by:

$$
E_{i}^{A}=\frac{\partial \log s_{i}^{*}}{\partial \log \operatorname{MINSTK}_{i}}+b_{3} \frac{\operatorname{MINSTK}_{i}}{\operatorname{MINSKTOT}_{2}}=a_{2}\left(1-s_{i}^{*}\right) \operatorname{MINSTK}_{i}+b_{3} \frac{\operatorname{MINSTK}_{i}}{\operatorname{MINSKTOT}^{\prime}}
$$

Here, $\bar{s}_{i 4}$ is the average share of drug $i$ during the period in which all four drugs are present.

In this model, consumption externalities attributable to past sales of the therapeutic category are captured by the coefficient $d_{0}$, while those attributable to past sales of the individual brand are captured by $d_{1}$. Note from the tables that $d_{1}$ is in most cases positive and significant, while $d_{0}$ is insignificant. We infer from this that consumption externalities connected with the rate of product diffusion occur primarily at the brand level. In other words, past sales of a specific brand - as opposed to the entire therapeutic class - contribute to the rate at which sales of that brand increases towards its saturation level.

Tables 5A, 5B, and 5C also show estimated total own-price elasticities, and total elasticities with respect to detailing minutes. The price elasticities are on the order of -0.5 to -0.7 , and the advertising elasticities are on the order of 1 to 1.3. Given that the marginal cost of production for $\mathrm{H}_{2}$-antagonist antiulcer drugs is very small (generally around 10 cents to 20 cents per daily dose), we would expect the own-price elasticities to be close to -1 if the producers are indeed maximizing profits. Thus these estimated price elasticities seem somewhat low. As explained earlier, the large advertising elasticities may reflect the rising marginal cost of detailing. 


\section{Simulations of the Model}

Simulations of the complete model can be used for at least two purposes. First, in-sample simulations provide a test of the model's validity. Specifically, by using historical values for the attributes, the prices, advertising levels, and population, we can solve for all of the other variables endogenously, in a dynamic framework, and assess how close the results are to the actual data. Second, we can use the model to simulate the effects of alternative strategies for pricing, detailing, and quality improvement. For example, we can examine how sales of the various brands would have evolved had Zantac detailed less, or had Zantac's attributes been the same as those of, say, Tagamet.

Because the model is highly nonlinear, the convergence and stability of the simulations are sensitive to the initial conditions. To deal with this, we simulate the full model using the actual values of sales for each brand for the first 12 months following the entry of the brand.

Figure 8 shows the simulated and actual sales for all four brands. The simulated series comes from a dynamic simulation of the entire model, where real prices, detailing minutes, attribute levels, and population are exogenous, and all other variables (quality-adjusted prices, quality-adjusted average price, equilibrium shares, the industry saturation level, and the sales of each brand) are solved for endogenously. Note that overall, the simulated values are quite close to the actual values. Table 6 displays simulation diagnostics for each of the four brands.

We then use the model to simulate the effects of changes in market conditions. We conducted four experiments:

- We set Zantac's nominal price in each month equal to that of Tagamet.

- We set Zantac's marketing level (detailing minutes) in each month equal to that of Tagamet.

- We set Zantac's marketing level equal to Tagamet's, and we also set its attributes equal to those of Tagamet. 
- We reduced $d_{1}$, the coefficient in the brand diffusion model that determines the impact of past sales on the rate of growth of current sales, by 50 percent (from 0.018 to 0.009 ).

The results of these simulations are summarized in Table 7, which shows the change in sales for each brand (the experiment minus the base case) in May 1993, the end of our sample. Table 7 also shows the resulting change in cumulative profits for Zantac and Tagamet under each experiment.

The results of the first experiment are shown in Figure 9. Here, Zantac's nominal price is equal to Tagamet's in each month. Recall that Zantac had better attributes than did Tagamet, so its quality-adjusted price is lower than Tagamet's. The figure compares two sets of simulated values - the simulated sales for each drug using the actual values of the exogenous variables, and the simulated sales for each drug using the actual values for all variables, except for setting Zantac's price equal to that of Tagamet. Observe from Figure 9 that Zantac's sales are about 20 percent higher than in the base case simulation - its lower quality-adjusted price results in an increase in its equilibrium share. What is surprising, however, is that the sales of Tagamet, Pepcid, and Axid are also higher than in the base case simulation. The reason is that even though their equilibrium shares are lower, the average industry price is now lower (because Zantac's price has been reduced), so that the industry saturation level, $X_{t}^{*}$, is higher. In this simulation, the effect of this higher saturation level outweighs the reductions in equilibrium shares.

The results of the second experiment, in which Zantac's detailing level is set equal to Tagamet's, are shown in Figure 10. Recall that Zantac detailed much more heavily than Tagamet, particularly during the first two years following its introduction. Thus in the experiment we are decreasing Zantac's detailing. The result is that Zantac's sales are much lower by the end of the period. Likewise, the sales of Tagamet, Axid, and Pepcid are all significantly higher. These results are due to the large values (about 1.0) of the advertising elasticities of demand estimated in the equilibrium share model. The reduction in Zantac's detailing thus leads to a large drop in its equilibrium share. Table 7 shows the impact on Zantac's cumulative gross profits, ignoring production costs (which are small), but accounting 
for detailing costs, which are estimated annually from aggregate pharmaceutical industry data. ${ }^{16}$ Observe that although Zantac's detailing expenditures drop, its sales drop by so much that its overall cumulative profits fall by almost $\$ 700$ million.

Figure 11 shows a simulation in which Zantac's attributes and its detailing level are set equal to those of Tagamet. In effect, we are increasing Zantac's quality-adjusted price (and reducing its detailing). This will reduce Zantac's equilibrium share and raise the equilibrium shares of Tagamet, Axid, and Pepcid. The results are close to those of Experiment (2). Because of the large estimated detailing elasticity of demand, Zantac's sales fall considerably.

Our last experiment evaluates the role of past sales as a determinant of the rate at which a brand diffuses into the market. This effect is captured by the coefficient $d_{1}$ in our brand diffusion model. Note from column (1) of Table 5B that the estimated value for this coefficient was 0.0180 . In our experiment, we reduce this coefficient by 50 percent, i.e., we set it equal to 0.0090. The result of the simulation is shown in Figure 12. Observe that Tagamet's sales grow much more slowly than in the base case simulation. (The reason is that past sales of Tagamet contribute less to the growth of sales as compared to the base case simulation.) The same is true, however, for Zantac, Pepcid, and Axid. As a result, by late 1984, after Zantac has entered the market, Tagamet's sales are higher than in the base case simulation. The reason is that Tagamet is now less harmed by the slower sales growth of Zantac (and, later, Pepcid and Axid). As can be seen from Table 7, the overall change in Tagamet's cumulative gross profits is small (it falls by about $\$ 25$ million). Zantac's cumulative gross profits, however, fall by nearly $\$ 900$ million. Thus we observe that past sales play a significant role in brand diffusion and profitability.

\footnotetext{
${ }^{16}$ We used average "Cost per Call" data, estimated each year for the pharmaceutical industry as a whole by IMS (IMS, 1996, pp. 7-47 and A-20), from a survey of manufacturers who estimate the direct expenses of keeping a representative "in the field" - salary, bonus, car, insurance, expenses, training, etc. IMS indicates that, on average, a call involves from two to four "product details," i.e., individual products discussed by the sales representative. In addition to the number of detailing minutes for each drug, we have data on the number of details per month for each drug. Aggregating these two series to the level of the entire $\mathrm{H}_{2^{-}}$ antagonist class, and assuming that each "call" comprises three "details," we compute an average annual cost per detailing minute from 1977 to 1993. In 1982 dollars, this average cost increases from $\$ 3.28$ in 1977 to $\$ 8.09$ in 1993.
} 


\section{Conclusions}

Our objective in this paper has been to identify the distinct ways in which consumption externalities influence the demands for prescription pharmaceuticals, and to obtain empirical estimates of their importance. We have focused on the case of $\mathrm{H}_{2}$-antagonists employed for antiulcer/heartburn treatments, but our approach could be applied to other well-defined therapeutic classes of prescription drugs. It could also be applied to other products for which information about efficacy and safety is conveyed by the usage of others.

Our results indicate that consumption externalities appear to operate at the brandspecific level. These effects are captured by introducing the depreciated stock of past sales, for the brand and for the therapeutic class, in both our hedonic price equations and our models of brand diffusion. We find that the brand-specific spillover variable is statistically significant in both cases, although its quantitative importance is modest.

Our hedonic equations show that past sales contributes to the value of a brand, but it only explains a few percent of a brand's value. However, its effect on the rate of diffusion is economically very significant. Our simulations imply that had the magnitude of this effect been 50 percent smaller, Zantac would have earned $\$ 882$ million less in gross profits, an amount roughly equivalent to three months of 1992 sales.

These results have important strategic implications. Our hedonic price equations suggest that pioneering firms benefit (in terms of consumer valuation) by being first to market and establishing a large installed base before another firm enters, but that this effect is modest. On the other hand, our brand-level diffusion equations suggest that rates of diffusion can be accelerated by a larger brand-specific installed base. Thus, even if the ultimate saturation level for a second entrant is close to that of a first entrant with similar attributes, the more rapid rate of diffusion can result in significantly greater profits.

In the case of $\mathrm{H}_{2}$-antagonist antiulcer drugs, this consumption externality was not large enough to prevent the second entrant from overcoming the pioneering brand. Our results also shed light on how Zantac prevailed. It derived little benefit from the information about $\mathrm{H}_{2^{-}}$ antagonists generated by Tagamet: free-riding from inter-brand consumption externalities is 
negligible. Instead, delayed entry allowed Glaxo to introduce a product with better quality attributes. Combined with a heavy detailing campaign, these superior attributes overcame whatever first-mover advantage Tagamet's installed base of patients may have represented. ${ }^{17}$

More generally, the results of this study concur with David (1997), who argues that lock-ins and positive feedbacks are neither necessary nor sufficient conditions for inefficient market outcomes to prevail. Consumption externalities of the type studied here constrain firms' optimal pricing and advertising decisions, but need not lead to significant inefficiencies.

\footnotetext{
${ }^{17}$ Anecdotal evidence suggests that these features are not unique to the antiulcer drug market. In the anti-hypertensive market, for example, Merck introduced its ACE Inhibitor Vasotec later than Bristol MyersSquibb's pioneer, Capoten. As recounted by Werth (1994), p. 58:

"Merck had put scores of chemists on the task of improving [Capoten], then followed up with a withering sales campaign so effective that it ended up beating Squibb in the market even though Capoten was launched first and was much the same drug."
} 


\section{References}

BanerJee, A. V., 1992, "A Simple Model of Herd Behavior," Quarterly Journal of Economics, $\mathbf{1 0 7}(3), 797-817$.

BAss, F. M., 1969, "A New Product Growth Model for Consumer Durables," Management Science, 15(1), 215-227.

Beggs, A. And P. Klemperer, 1992, "Multi-Period Competition with Switching Costs," Econometrica, 60(3), 651-666.

Berndt, E. R., 1991, The Practice of Econometrics: Classic and Contemporary, Reading, MA: Addison-Wesley Publishing Co.

Berndt, E. R., Cockburn I. M. and Z. Griliches, 1996, "Pharmaceutical Innovations and Market Dynamics: Tracking Effects on Price Indexes for Antidepressant Drugs," Brookings Paper on Economic Activity: Microeconomics, 133-188.

Berndt, E. R., Bui, L. T., Lucking-Reiley, D. H. and G. L. Urban, 1997, "The Roles of Marketing, Product Quality, and Price Competition in the Growth and Composition of the U.S. Antiulcer Drug Industry," in T. F. Bresnahan and R. J. Gordon, eds., The Economics of New Goods, 58, NBER Studies in Income and Wealth, Chicago: University of Chicago Press, 277-322.

Berndt, E. R., Bui, L. T., Lucking-Reiley, D. H. and G. L. Urban, 1995, "Information, Marketing, and Pricing in the U.S. Antiulcer Drug Market," American Economic Review, Papers and Proceedings of the $107^{\text {th }}$ Meetings of the American Economic Association, 85(2), 100-105.

Berry, S., 1994, "Estimating Discrete-Choice Models of Product Differentiation," RAND Journal of Economics, 25(2), 242-262.

Berry, S., Levinsohn J. And A. Pakes, 1995, "Automobile Prices in Market Equilibrium," Econometrica, 60(4), 889-917.

Besen, S. M. And J. Farrell, 1994, "Choosing How to Compete: Strategies and Tactics in Standardization," Journal of Economic Perspectives, 8(2), 117-131.

Bhattacharyja, A. S., 1994, "Product Experimentation and Learning Under Reswitching," Working Paper, Econometric Society Meetings.

Bikhchandani, S., Hirshleifer D. And I. Welch, 1998, "Learning from the Behavior of Others: Conformity, Fads, and Informational Cascades," Journal of Economic Perspectives, 12(3), 151-170. 
Bond, R. S. And D. F. Lean, 1977, "Sales, Promotion, and Product Differentiation in Two Prescription Drug Markets," Staff Report to the FTC, Federal Trade Commission, Washington, D.C.

Brynjolfsson, E. And C. F. Kemerer, 1996, "Network Externalities in Microcomputer Software: An Econometric Analysis of the Spreadsheet Market," Management Science, 42(12), 16271647.

Choi, J. P., 1997, "Herd Behavior, the 'Penguin Effect,' and the Suppression of Informational Diffusion: An Analysis of Informational Externalities and Payoff Interdependency," RAND Journal of Economics, 28(3), 407-425.

Cockburn, I. And A. H. Anis, 1998, "Hedonic Analysis of Arthritis Drugs," NBER Working Paper \#65\%4.

Coleman, J. S., Katz, E. And H. Menzel, 1966, Medical Innovation: A Diffusion Study, New York: Bobbs-Merrill.

David, P., 1997, "Path Dependence and the Quest for Historical Economics: One More Chorus of the Ballad of QWERTY," Working Paper, Oxford University.

Ellison, S. F., Cockburn, I., Griliches, Z. And J. Hausman, 1997, "Characteristics of Demand for Pharmaceutical Products: An Examination of Four Cephalosporins," RAND Journal of Economics, 28(3), 426-446.

Gandal, N., 1994, "Hedonic Price Indexes for Spreadsheets and an Empirical Test for Network Externalities," RAND Journal of Economics, 25(1), 160-170.

Gandal, N., Kende, M. And R. Rob, 2000, "The Dynamics of Technological Adoption in Hardware/Software Systems: The Case of Compact Disc Players," RAND Journal of Economics, 31(1), 43-61.

Goolsbee, A. And P. J. Klenow, 1999, "Evidence on Network and Learning Externalities in the Diffusion of Home Computers," NBER Working Paper \#7329.

Griliches, Z., 1957, "Hybrid Corn: An Exploration in the Economics of Technological Change," Econometrica, 25(4), 501-522.

Griliches, Z., 1958, "Research Costs and Social Returns: Hybrid Corn and Related Innovations," Journal of Political Economy, 66(5), 419-431.

Griliches, Z., 1990, "Patent Statistics as Economic Indicators: A Survey," Journal of Economic Literature, 28(4), 1661-1707. 
IMS AmerICA, 1996, Information Services Manual, Philadelphia: IMS Publications.

Kessler, D. and M. McClellan, 1996, "Do Doctors Practice Defensive Medicine?," Quarterly Journal of Economics, 111(2), 353-390.

King, C., 1998, "Marketing, Product Differentiation, and Competition in the Market for Antiulcer Drugs," Working Paper, Harvard Business School.

Lu, Z. J. And W. S. Comanor, 1998, "Strategic Pricing of New Pharmaceuticals," Review of Economics and Statistics, 80(1), 108-118.

Mahajan, V. And E. Muller, 1979, "Innovation Diffusion and New Product Growth Models in Marketing," Journal of Marketing, 43(4), 55-68.

Mahajan, V., Muller E. And F. M. Bass, 1990, "New Product Diffusion Models in Marketing: A Review and Directions for Research," Journal of Marketing, 54(1), 1-26.

McFadden, D., 1984, "Econometric Analysis of Qualitative Response Models," in Z. Griliches and M. D. Intriligator, eds., Handbook of Econometrics, 2, New York: North-Holland, 1396-1457.

Pindyck, R. S. And D. L. Rubinfeld, 1997, Econometric Models and Economic Forecasts, Fourth Edition, New York: McGraw Hill.

Scharfstein, D. And J. Stein, 1990, "Herd Behavior and Investment," American Economic Review 80(3), 465-479.

Suslow, V. Y., 1996, "Measuring Quality Change in the Market for Anti-Ulcer Drugs," in R. B. Helms, ed., Competitive Strategies in the Pharmaceutical Industry, Washington, D.C.: The AEI Press, 49-72.

Werth, B., 1994, The Billion-Dollar Molecule, New York: Simon \& Schuster. 


\section{Table 1. Summary Statistics}

\begin{tabular}{|c|c|c|c|c|}
\hline & Mean & Std Dev & Minimum & Maximum \\
\hline \multicolumn{5}{|c|}{ A. Industry Variables (Nobs $=188)$} \\
\hline$X_{t}\left(\right.$ patient-days $/$ month, $\left.\times 10^{6}\right)$ & 51.75 & 25.57 & 3.773 & 99.05 \\
\hline $\mathrm{XS}_{t}$ (cumul. patient-days, $\times 10^{6}$ ) & 1028.4 & 619.7 & 7.715 & 2099.3 \\
\hline $\bar{P}_{t}$ (quality-adjusted avg. price) & 1.562 & 0.215 & 1.155 & 1.914 \\
\hline $\bar{p}_{t}($ real avg. price, $1982 \$)$ & 1.206 & 0.441 & 0.688 & 1.930 \\
\hline $\mathrm{POP}_{t}$ (U.S. population, $\times 10^{6}$ ) & 237.3 & 10.34 & 219.4 & 256.2 \\
\hline $\mathrm{MIN}_{t}$ (detailing minutes, $\times 10^{6}$ ) & 0.249 & 0.171 & 0.019 & 0.604 \\
\hline MINSTKTOT $_{t}$ (ind. tot. stock min., $\times 10^{6}$ ) & 4.173 & 3.107 & 0.263 & 9.268 \\
\hline \multicolumn{5}{|c|}{ B. Tagamet $($ Nobs $=188)$} \\
\hline$X_{i t}\left(\right.$ patient-days $/$ month, $\left.\times 10^{6}\right)$ & 27.52 & 9.087 & 3.773 & 46.42 \\
\hline $\mathrm{XS}_{i t}$ (cumul. patient-days, $\times 10^{6}$ ) & 615.0 & 259.0 & 7.715 & 872.6 \\
\hline$P_{i t}$ (quality-adjusted price) & 1.562 & 0.232 & 1.155 & 2.004 \\
\hline$p_{i t}($ real price, $1982 \$)$ & 1.056 & 0.328 & 0.688 & 1.700 \\
\hline $\operatorname{MIN}_{i t}$ (detailing minutes, $\times 10^{6}$ ) & 0.094 & 0.036 & 0.019 & 0.199 \\
\hline $\operatorname{MINSTK}_{i t}\left(\right.$ stock of minutes, $\left.\times 10^{6}\right)$ & 1.727 & 0.656 & 0.263 & 2.576 \\
\hline GERD $_{i t}$ (GERD dummy) & 0.133 & 0.340 & 0.000 & 1.000 \\
\hline SUMATT $_{i t}$ (other approved indications) & 1.612 & 0.873 & 0.000 & 3.000 \\
\hline INTER $_{i t}(\#$ adverse drug interactions) & 7.096 & 3.617 & 0.000 & 10.00 \\
\hline $\operatorname{DOSAGE}_{i t}$ (daily dosing frequency) & 2.516 & 1.416 & 1.000 & 4.000 \\
\hline \multicolumn{5}{|c|}{ C. Zantac $($ Nobs $=117)$} \\
\hline$X_{i t}\left(\right.$ patient-days $/$ month, $\left.\times 10^{6}\right)$ & 30.42 & 14.20 & 4.190 & 54.27 \\
\hline $\mathrm{XS}_{i t}$ (cumul. patient-days, $\times 10^{6}$ ) & 537.8 & 337.9 & 11.92 & 1093.2 \\
\hline$P_{i t}$ (quality-adjusted price) & 1.733 & 0.108 & 1.533 & 1.961 \\
\hline$p_{i t}($ real price, $1982 \$)$ & 1.770 & 0.239 & 1.309 & 2.129 \\
\hline $\mathrm{MIN}_{i t}$ (detailing minutes, $\times 10^{6}$ ) & 0.133 & 0.036 & 0.048 & 0.212 \\
\hline $\operatorname{MINSTK}_{i t}\left(\right.$ stock of minutes, $\left.\times 10^{6}\right)$ & 2.289 & 0.667 & 0.704 & 3.049 \\
\hline GERD $_{i t}$ (GERD dummy) & 0.718 & 0.452 & 0.000 & 1.000 \\
\hline SUMATT $_{i t}$ (other approved indications) & 1.530 & 0.794 & 0.000 & 2.000 \\
\hline $\operatorname{INTER}_{i t}$ (\# adverse drug interactions) & 0.145 & 0.354 & 0.000 & 1.000 \\
\hline $\operatorname{DOSAGE}_{i t}$ (daily dosing frequency) & 1.342 & 0.476 & 1.000 & 2.000 \\
\hline
\end{tabular}


Table 1. Summary Statistics (continued)

\begin{tabular}{|c|c|c|c|c|}
\hline & Mean & Std Dev & Minimum & Maximum \\
\hline \multicolumn{5}{|c|}{ D. Pepcid $($ Nobs $=77)$} \\
\hline$X_{i t}$ (patient-days/month, $\left.\times 10^{6}\right)$ & 9.173 & 3.693 & 1.947 & 14.61 \\
\hline $\mathrm{XS}_{i t}$ (cumul. patient-days, $\times 10^{6}$ ) & 141.7 & 86.62 & 4.740 & 284.0 \\
\hline$P_{i t}$ (quality-adjusted price) & 1.695 & 0.117 & 0.417 & 1.892 \\
\hline$p_{i t}($ real price, $1982 \$)$ & 1.616 & 0.123 & 1.286 & 1.844 \\
\hline $\operatorname{MIN}_{i t}$ (detailing minutes, $\times 10^{6}$ ) & 0.075 & 0.023 & 0.031 & 0.131 \\
\hline $\operatorname{MINSTK}_{i t}\left(\right.$ stock of minutes, $\left.\times 10^{6}\right)$ & 1.211 & 0.389 & 0.295 & 1.645 \\
\hline $\operatorname{GERD}_{i t}($ GERD dummy) & 0.234 & 0.426 & 0.000 & 1.000 \\
\hline SUMATT $_{i t}$ (other approved indications) & 1.727 & 0.448 & 1.000 & 2.000 \\
\hline $\mathrm{INTER}_{i t}$ (\# adverse drug interactions) & 0.000 & 0.000 & 0.000 & 0.000 \\
\hline DOSAGE $_{i t}$ (daily dosing frequency) & 1.000 & 0.000 & 1.000 & 1.000 \\
\hline \multicolumn{5}{|c|}{ E. Axid (Nobs $=59)$} \\
\hline$X_{i t}$ (patient-days/month, $\times 10^{6}$ ) & 4.926 & 2.344 & 0.704 & 9.207 \\
\hline $\mathrm{XS}_{i t}$ (cumul. patient-days, $\times 10^{6}$ ) & 65.16 & 41.80 & 4.568 & 146.6 \\
\hline$P_{i t}$ (quality-adjusted price) & 1.778 & 0.090 & 1.630 & 1.964 \\
\hline$p_{i t}($ real price, $1982 \$)$ & 1.680 & 0.169 & 1.456 & 1.943 \\
\hline $\operatorname{MIN}_{i t}$ (detailing minutes, $\times 10^{6}$ ) & 0.114 & 0.024 & 0.069 & 0.217 \\
\hline $\operatorname{MINSTK}_{i t}\left(\right.$ stock of minutes, $\left.\times 10^{6}\right)$ & 1.647 & 0.517 & 0.427 & 2.277 \\
\hline GERD $_{i t}($ GERD dummy) & 0.390 & 0.492 & 0.000 & 1.000 \\
\hline SUMATT $_{i t}$ (other approved indications) & 1.000 & 0.000 & 1.000 & 1.000 \\
\hline INTER $_{i t}$ (\# adverse drug interactions) & 1.000 & 0.000 & 1.000 & 1.000 \\
\hline DOSAGE $_{i t}$ (daily dosing frequency) & 1.000 & 0.000 & 1.000 & 1.000 \\
\hline \multicolumn{5}{|c|}{ F. Balanced Panel, 1989-1993 (Nobs = 53) } \\
\hline$S_{i t}$ - Tagamet & 0.293 & 0.059 & 0.212 & 0.407 \\
\hline$S_{i t}-$ Zantac & 0.519 & 0.018 & 0.478 & 0.550 \\
\hline$S_{i t}-$ Pepcid & 0.130 & 0.023 & 0.079 & 0.169 \\
\hline$S_{i t}-$ Axid & 0.058 & 0.023 & 0.011 & 0.094 \\
\hline$P_{i t}$ - Tagamet & 1.854 & 0.093 & 1.709 & 2.004 \\
\hline$P_{i t}-$ Zantac & 1.808 & 0.086 & 1.673 & 1.961 \\
\hline$P_{i t}-$ Pepcid & 1.738 & 0.106 & 1.542 & 1.892 \\
\hline$P_{i t}-$ Axid & 1.790 & 0.088 & 1.630 & 1.964 \\
\hline MINSTK $_{i t}$ - Tagamet & 2.343 & 0.221 & 1.713 & 2.538 \\
\hline MINSTK $_{i t}-$ Zantac & 2.895 & 0.099 & 2.535 & 3.049 \\
\hline MINSTK $_{i t}-$ Pepcid & 1.450 & 0.154 & 1.030 & 1.645 \\
\hline MINSTK $_{i t}-$ Axid & 1.758 & 0.415 & 0.914 & 2.277 \\
\hline
\end{tabular}




\section{Table 2. Hedonic Price Equation}

\begin{tabular}{|c|c|c|c|c|c|c|}
\hline & \multicolumn{3}{|c|}{ A. Dependent Variable $=P_{j t}$} & \multicolumn{3}{|c|}{ B. $\underline{\text { Dependent Variable }=\log P_{j t}}$} \\
\hline & (1) & (2) & (3) & (4) & $(5)$ & (6) \\
\hline Const. & $\begin{array}{l}1.3535 \\
(18.82)\end{array}$ & $\begin{array}{l}1.4152 \\
(18.44)\end{array}$ & $\begin{array}{l}1.3919 \\
(17.64)\end{array}$ & $\begin{array}{c}0.5113 \\
(7.47)\end{array}$ & $\begin{array}{l}0.5467 \\
(7.45)\end{array}$ & $\begin{array}{l}0.5387 \\
(7.21)\end{array}$ \\
\hline $\mathrm{GERD}_{i t}$ & $\begin{array}{l}0.1816 \\
(10.72)\end{array}$ & $\begin{array}{l}0.2320 \\
(13.48)\end{array}$ & $\begin{array}{l}0.1820 \\
(10.71)\end{array}$ & $\begin{array}{l}0.1245 \\
(10.50)\end{array}$ & $\begin{array}{l}0.1418 \\
(13.40)\end{array}$ & $\begin{array}{l}0.1247 \\
(10.48)\end{array}$ \\
\hline SUMATT $_{i t}$ & $\begin{array}{c}-0.0159 \\
(-0.98)\end{array}$ & $\begin{array}{c}0.0163 \\
(1.11)\end{array}$ & $\begin{array}{c}-0.0156 \\
(-0.97)\end{array}$ & $\begin{array}{c}-0.0061 \\
(-0.49)\end{array}$ & $\begin{array}{l}0.0050 \\
(0.46)\end{array}$ & $\begin{array}{c}-0.0059 \\
(-0.48)\end{array}$ \\
\hline INTER $_{i t}$ & $\begin{array}{l}-0.0452 \\
(-16.62)\end{array}$ & $\begin{array}{l}-0.0375 \\
(-14.37)\end{array}$ & $\begin{array}{l}-0.0452 \\
(-16.59)\end{array}$ & $\begin{array}{l}-0.0286 \\
(-14.33)\end{array}$ & $\begin{array}{l}-0.0259 \\
(-14.56)\end{array}$ & $\begin{array}{l}-0.0285 \\
(-14.29)\end{array}$ \\
\hline $\operatorname{DOSAGE}_{i t}$ & $\begin{array}{c}-0.1158 \\
(-6.83)\end{array}$ & $\begin{array}{c}-0.1194 \\
(-7.41)\end{array}$ & $\begin{array}{c}-0.1157 \\
(-6.83)\end{array}$ & $\begin{array}{c}-0.1555 \\
(-9.63)\end{array}$ & $\begin{array}{c}-0.1566 \\
(-9.91)\end{array}$ & $\begin{array}{c}-0.1554 \\
(-9.64)\end{array}$ \\
\hline $\mathrm{XS}_{i t}(-1)$ & $\begin{array}{c}.1758 \times 10^{-3} \\
(5.49)\end{array}$ & & $\begin{array}{c}.1753 \times 10^{-3} \\
(5.48)\end{array}$ & $\begin{array}{c}.6030 \times 10^{-4} \\
(2.72)\end{array}$ & & $\begin{array}{c}.5998 \times 10^{-4} \\
(2.71)\end{array}$ \\
\hline $\mathrm{XS}_{t}(-1)$ & & $\begin{array}{c}.4804 \times 10^{-3} \\
(1.79)\end{array}$ & $\begin{array}{c}.4265 \times 10^{-3} \\
(1.50)\end{array}$ & & $\begin{array}{c}.0239 \times 10^{-3} \\
(1.45)\end{array}$ & $\begin{array}{c}.3054 \times 10^{-3} \\
(1.34)\end{array}$ \\
\hline$R^{2}$ & .966 & .960 & .967 & .970 & .969 & .970 \\
\hline $\begin{array}{l}\text { Zantac Price } \\
\text { Premium }\end{array}$ & $\$ 0.01$ & $\$ 0.35$ & $\$ 0.30$ & $\$ 0.04$ & $\$ 0.27$ & $\$ 0.25$ \\
\hline
\end{tabular}

Note: All regressions include annual and quarterly time dummies; NOB $=441 ; t$-statistics (from heteroscedasticity-consistent and $\operatorname{ARMA}(2,2)$ serial-correlation consistent standard errors) in parentheses. Zantac price premium is the estimated quality-adjusted price of Zantac minus that of Tagamet at the time of Zantac's entry in July 1983, based on attribute differences with Tagamet. (The actual deflated price difference was $\$ 0.615$.) 


\section{Table 3. Estimates of Equilibrium Logit Market Shares, 1989-1993}

(Omitted Share is Tagamet, NOBS $=53$ )

\begin{tabular}{|c|c|c|c|c|}
\hline & & $\begin{array}{c}(1) \\
\text { SUR }\end{array}$ & $\begin{array}{c}(2) \\
3 S L S\end{array}$ & $\begin{array}{c}(3) \\
\text { GMM }\end{array}$ \\
\hline \multicolumn{2}{|c|}{ Intercept-Zantac } & $\begin{array}{l}0.1983 \\
(10.47)\end{array}$ & $\begin{array}{c}0.1937 \\
(10.14)\end{array}$ & $\begin{array}{l}0.2055 \\
(14.89)\end{array}$ \\
\hline \multicolumn{2}{|c|}{ Intercept-Pepcid } & $\begin{array}{c}-0.0817 \\
(-3.33)\end{array}$ & $\begin{array}{c}-0.0788 \\
(-3.16)\end{array}$ & $\begin{array}{c}-0.0957 \\
(-4.31)\end{array}$ \\
\hline \multicolumn{2}{|c|}{ Intercept-Axid } & $\begin{array}{l}-1.1067 \\
(-73.38)\end{array}$ & $\begin{array}{l}-1.1045 \\
(-71.23)\end{array}$ & $\begin{array}{l}-1.1047 \\
(-87.50)\end{array}$ \\
\hline \multicolumn{2}{|l|}{$a_{1}$} & $\begin{array}{c}-0.2889 \\
(-4.76)\end{array}$ & $\begin{array}{c}-0.3129 \\
(-4.90)\end{array}$ & $\begin{array}{c}-0.3442 \\
(-5.91)\end{array}$ \\
\hline \multicolumn{2}{|l|}{$a_{2}$} & $\begin{array}{l}0.7634 \\
(32.08)\end{array}$ & $\begin{array}{c}0.7697 \\
(31.53)\end{array}$ & $\begin{array}{l}0.7414 \\
(43.12)\end{array}$ \\
\hline \multicolumn{2}{|l|}{$R^{2}$} & $.78 / .81 / .96$ & $.78 / .81 / .96$ & $.77 / .81 / .96$ \\
\hline \multirow[t]{4}{*}{$\epsilon_{P}$} & Tagamet & $\begin{array}{c}-0.385 \\
(-4.757)\end{array}$ & $\begin{array}{c}-0.417 \\
(-4.897)\end{array}$ & $\begin{array}{c}-0.459 \\
(-5.908)\end{array}$ \\
\hline & Zantac & $\begin{array}{c}-0.250 \\
(-4.757)\end{array}$ & $\begin{array}{c}-0.271 \\
(-4.897)\end{array}$ & $\begin{array}{c}-0.298 \\
(-5.908)\end{array}$ \\
\hline & Pepcid & $\begin{array}{c}-0.435 \\
(-4.757)\end{array}$ & $\begin{array}{c}-0.471 \\
(-4.897)\end{array}$ & $\begin{array}{c}-0.518 \\
(-5.908)\end{array}$ \\
\hline & Axid & $\begin{array}{c}-0.485 \\
(-4.757)\end{array}$ & $\begin{array}{c}-0.525 \\
(-4.897)\end{array}$ & $\begin{array}{c}-0.577 \\
(-5.908)\end{array}$ \\
\hline \multirow[t]{4}{*}{$\epsilon_{\mathrm{MIN}}$} & Tagamet & $\begin{array}{c}1.286 \\
(32.078)\end{array}$ & $\begin{array}{c}1.297 \\
(31.534)\end{array}$ & $\begin{array}{c}1.249 \\
(43.119)\end{array}$ \\
\hline & Zantac & $\begin{array}{c}1.057 \\
(32.078)\end{array}$ & $\begin{array}{c}1.066 \\
(31.534)\end{array}$ & $\begin{array}{c}1.027 \\
(43.119)\end{array}$ \\
\hline & Pepcid & $\begin{array}{c}0.958 \\
(32.078)\end{array}$ & $\begin{array}{c}0.966 \\
(31.534)\end{array}$ & $\begin{array}{c}0.930 \\
(43.119)\end{array}$ \\
\hline & Axid & $\begin{array}{c}1.258 \\
(32.078)\end{array}$ & $\begin{array}{c}1.268 \\
(31.534)\end{array}$ & $\begin{array}{c}1.222 \\
(43.119)\end{array}$ \\
\hline
\end{tabular}

Note: For models (1) and (2), $t$-statistics (from heteroscedasticity-consistent standard errors) are in parentheses. For model (2), the Hausman test statistic for exogeneity of price and advertising is $6.486(\mathrm{p}=.090)$. For model $(3)$, the $t$-statistics are from heteroscedasticityconsistent and ARMA $(1,1)$ serial-correlation-consistent standard errors; the $J$-statistic for the test of overidentifying restrictions is $16.618, \mathrm{df}=10, \mathrm{p}=.083$. The price and advertising elasticities are computed at the point of means for the 1989-1993 sample period. 


\section{Table 4A. Industry Diffusion Models, One-Month Difference NOBS $=188$}

\begin{tabular}{|c|c|c|c|c|}
\hline Past Sales & $\begin{array}{c}(1) \\
X_{t-1}\end{array}$ & $\begin{array}{c}(2) \\
X S_{t-1}\end{array}$ & $\begin{array}{c}(3) \\
\log \left[\mathrm{XS}_{t-1}\right]\end{array}$ & $\begin{array}{c}(4) \\
\log \left[\mathrm{XS}_{t-1}\right]\end{array}$ \\
\hline$C_{0}$ & $\begin{array}{c}0.0169 \\
(0.16)\end{array}$ & $\begin{array}{c}-0.8196 \\
(-0.35)\end{array}$ & $\begin{array}{c}-0.5072 \\
(-2.57)\end{array}$ & $\begin{array}{c}-15.226 \\
(-3.27)\end{array}$ \\
\hline$d_{0}$ & $\begin{array}{c}.6268 \times 10^{-3} \\
(8.32)\end{array}$ & $\begin{array}{c}0.0402 \\
(9.80)\end{array}$ & $\begin{array}{c}0.1646 \\
(5.60)\end{array}$ & $\begin{array}{c}5.2535 \\
(5.05)\end{array}$ \\
\hline$b_{0}$ & $\begin{array}{l}0.1907 \\
(15.49)\end{array}$ & $\begin{array}{c}-34.305 \\
(-8.50)\end{array}$ & $\begin{array}{c}0.1670 \\
(11.78)\end{array}$ & $\begin{array}{c}-28.676 \\
(-2.67)\end{array}$ \\
\hline$b_{1}$ & $\begin{array}{c}-0.0544 \\
(-5.60)\end{array}$ & $\begin{array}{c}-0.3895 \\
(-1.80)\end{array}$ & $\begin{array}{c}-0.0509 \\
(-5.02)\end{array}$ & $\begin{array}{c}-0.2344 \\
(0.56)\end{array}$ \\
\hline$b_{2}$ & & $\begin{array}{c}6.9853 \\
(9.26)\end{array}$ & & $\begin{array}{l}5.8935 \\
(2.96)\end{array}$ \\
\hline$b_{3}$ & $\begin{array}{c}.2988 \times 10^{-3} \\
(0.43)\end{array}$ & $\begin{array}{c}0.1775 \\
(5.75)\end{array}$ & $\begin{array}{c}-0.0012 \\
(-1.55)\end{array}$ & $\begin{array}{c}0.2984 \\
(2.49)\end{array}$ \\
\hline$\beta$ & $\begin{array}{l}0.0076 \\
(12.21)\end{array}$ & & $\begin{array}{c}0.0099 \\
(11.00)\end{array}$ & \\
\hline$R^{2}$ & .410 & .398 & .340 & .184 \\
\hline
\end{tabular}

Note: In each model, the consumption externality is $\mathrm{CE}_{t}=\mathrm{XS}_{t}$ or $\log \left[\mathrm{XS}_{t}\right]$. Models (1) and (3):

$$
\begin{aligned}
& \Delta X_{t}=\left(X_{t}^{*}-X_{t-1}\right)\left(C_{0}+\sum_{k=2}^{12} \theta_{k} m_{k t}+d_{0} \mathrm{CE}_{t-1}\right) \text { and } \\
& X_{t}^{*}=\left(b_{0}+b_{1} \bar{P}_{t}+b_{3} \text { MINSTKTOT }_{t}\right) \mathrm{POP}_{t} e^{\beta t}
\end{aligned}
$$

Models (2) and (4):

$$
\begin{aligned}
& \Delta X_{t}=\left(\log X_{t}^{*}-\log X_{t-1}\right)\left(C_{0}+\sum_{k=2}^{12} \theta_{k} m_{k t}+d_{0} \mathrm{CE}_{t-1}\right) \text { and } \\
& \log X_{t}^{*}=b_{0}+b_{1} \log \bar{P}_{t}+b_{2} \log \mathrm{POP}_{t}+b_{3} \log \mathrm{MINSTKTOT}_{t}
\end{aligned}
$$

The $m_{k t}$ 's are a set of monthly dummies whose coefficients $\theta_{k}$ are not reported. Numbers in parentheses are $t$-statistics from heteroscedasticity-consistent standard errors. In models (1) and (3), the estimated long-run price elasticities of demand, computed at the point of means, are $-0.81(-4.70)$ and $-0.94(-4.33)$, respectively, for the period 1977-1993. For the period 1989-1993, the elasticities are $-1.04(-4.13)$ and $-1.41(-3.74)$, respectively. 


\section{Table 4B. Industry Diffusion Models, Three-Month Difference NOBS $=185$}

\begin{tabular}{|c|c|c|c|c|}
\hline Past Sales & $\begin{array}{c}(1) \\
\mathrm{XS}_{t-3}\end{array}$ & $\begin{array}{c}(2) \\
\mathrm{XS}_{t-3}\end{array}$ & $\begin{array}{c}(3) \\
\log \left[\mathrm{XS}_{t-3}\right]\end{array}$ & $\begin{array}{c}(4) \\
\log \left[\mathrm{XS}_{t-3}\right]\end{array}$ \\
\hline$C_{0}$ & $\begin{array}{c}0.0979 \\
(1.07)\end{array}$ & $\begin{array}{c}0.9162 \\
(0.54)\end{array}$ & $\begin{array}{c}-0.2653 \\
(-1.70)\end{array}$ & $\begin{array}{c}-7.9582 \\
(-2.49)\end{array}$ \\
\hline$d_{0}$ & $\begin{array}{c}.4646 \times 10^{-3} \\
(6.83)\end{array}$ & $\begin{array}{c}0.0320 \\
(8.30)\end{array}$ & $\begin{array}{c}0.1200 \\
(4.66)\end{array}$ & $\begin{array}{l}3.9017 \\
(4.07)\end{array}$ \\
\hline$b_{0}$ & $\begin{array}{l}0.1953 \\
(13.67)\end{array}$ & $\begin{array}{c}-38.754 \\
(-8.01)\end{array}$ & $\begin{array}{l}0.1706 \\
(11.01)\end{array}$ & $\begin{array}{c}-39.192 \\
(-3.03)\end{array}$ \\
\hline$b_{1}$ & $\begin{array}{c}-0.0558 \\
(-5.01)\end{array}$ & $\begin{array}{c}-0.6337 \\
(-2.42)\end{array}$ & $\begin{array}{c}-0.0510 \\
(-4.61)\end{array}$ & $\begin{array}{c}-0.1786 \\
(-0.34)\end{array}$ \\
\hline$b_{2}$ & & $\begin{array}{l}7.8273 \\
(8.65)\end{array}$ & & $\begin{array}{l}7.8690 \\
(3.27)\end{array}$ \\
\hline$b_{3}$ & $\begin{array}{c}.6234 \times 10^{-4} \\
(0.08)\end{array}$ & $\begin{array}{c}0.1538 \\
(4.26)\end{array}$ & $\begin{array}{c}-0.0014 \\
(-1.67)\end{array}$ & $\begin{array}{l}0.1615 \\
(1.71)\end{array}$ \\
\hline$\beta$ & $\begin{array}{l}0.0076 \\
(10.45)\end{array}$ & & $\begin{array}{c}0.0098 \\
(9.87)\end{array}$ & \\
\hline$R^{2}$ & .347 & .339 & .295 & .150 \\
\hline
\end{tabular}

Note: In each model, the consumption externality is $\mathrm{CE}_{t}=\mathrm{XS}_{t}$ or $\log \left[\mathrm{XS}_{t}\right]$. Models (1) and (3):

$$
\begin{aligned}
& X_{t}-X_{t-3}=\left(X_{t}^{*}-X_{t-3}\right)\left(C_{0}+\sum_{k=2}^{12} \theta_{k} m_{k t}+d_{0} \mathrm{CE}_{t-3}\right) \text { and } \\
& X_{t}^{*}=\left(b_{0}+b_{1} \bar{P}_{t}+b_{3} \mathrm{MINSTKTOT}_{t}\right) \mathrm{POP}_{t} e^{\beta t}
\end{aligned}
$$

Models (2) and (4):

$$
\begin{aligned}
& X_{t}-X_{t-3}=\left(\log X_{t}^{*}-\log X_{t-3}\right)\left(C_{0}+\sum_{k=2}^{12} \theta_{k} m_{k t}+d_{0} \mathrm{CE}_{t-3}\right) \text { and } \\
& \log X_{t}^{*}=b_{0}+b_{1} \log \bar{P}_{t}+b_{2} \log \mathrm{POP}_{t}+b_{3} \log \mathrm{MINSTKTOT}_{t}
\end{aligned}
$$

The $m_{k t}$ 's are a set of monthly dummies whose coefficients $\theta_{k}$ are not reported. Numbers in parentheses are $t$-statistics from heteroscedasticity-consistent standard errors. In models (1) and (3), the estimated long-run price elasticities of demand, computed at the point of means, are $-0.83(-4.18)$ and $-0.942(-3.985)$, respectively, for the period 1977-1993. For the period 1989-1993, the elasticities are $-1.06(-3.66)$ and $-1.40(-3.38)$, respectively. 


\section{Table 4C. Industry Diffusion Models, Six-Month Difference NOBS $=182$}

\begin{tabular}{|c|c|c|c|c|}
\hline Past Sales & $\begin{array}{c}(1) \\
X S_{t-6}\end{array}$ & $\begin{array}{c}(2) \\
\mathrm{XS}_{t-6}\end{array}$ & $\begin{array}{c}(3) \\
\log \left[\mathrm{XS}_{t-6}\right]\end{array}$ & $\begin{array}{c}(4) \\
\log \left[X S_{t-6}\right]\end{array}$ \\
\hline$C_{0}$ & $\begin{array}{c}0.0995 \\
(1.05)\end{array}$ & $\begin{array}{c}-0.3113 \\
(-0.10)\end{array}$ & $\begin{array}{c}-0.1615 \\
(-0.91)\end{array}$ & $\begin{array}{c}-10.681 \\
(-1.87)\end{array}$ \\
\hline$d_{0}$ & $\begin{array}{c}.4920 \times 10^{-3} \\
(6.94)\end{array}$ & $\begin{array}{c}0.0371 \\
(8.90)\end{array}$ & $\begin{array}{c}0.0949 \\
(3.73)\end{array}$ & $\begin{array}{l}3.9967 \\
(3.85)\end{array}$ \\
\hline$b_{0}$ & $\begin{array}{l}0.2034 \\
(15.15)\end{array}$ & $\begin{array}{c}-39.951 \\
(-8.76)\end{array}$ & $\begin{array}{l}0.1678 \\
(12.57)\end{array}$ & $\begin{array}{c}-47.412 \\
(-3.55)\end{array}$ \\
\hline$b_{1}$ & $\begin{array}{c}-0.0586 \\
(-5.65)\end{array}$ & $\begin{array}{c}-0.6813 \\
(-2.81)\end{array}$ & $\begin{array}{c}-0.0512 \\
(-5.86)\end{array}$ & $\begin{array}{c}-0.3412 \\
(-0.65)\end{array}$ \\
\hline$b_{2}$ & & $\begin{array}{c}8.0544 \\
(9.43)\end{array}$ & & $\begin{array}{l}9.4018 \\
(3.78)\end{array}$ \\
\hline$b_{3}$ & $\begin{array}{c}.1687 \times 10^{-3} \\
(0.21)\end{array}$ & $\begin{array}{c}0.1405 \\
(4.19)\end{array}$ & $\begin{array}{c}-0.0022 \\
(-3.42)\end{array}$ & $\begin{array}{l}0.1197 \\
(1.28)\end{array}$ \\
\hline$\beta$ & $\begin{array}{l}0.0073 \\
(10.50)\end{array}$ & & $\begin{array}{l}0.0109 \\
(11.62)\end{array}$ & \\
\hline$R^{2}$ & .438 & .414 & .387 & .190 \\
\hline
\end{tabular}

Note: In each model, the consumption externality is $\mathrm{CE}_{t}=\mathrm{XS}_{t}$ or $\log \left[\mathrm{XS}_{t}\right]$. Models (1) and (3):

$$
\begin{aligned}
& X_{t}-X_{t-6}=\left(X_{t}^{*}-X_{t-6}\right)\left(C_{0}+\sum_{k=2}^{12} \theta_{k} m_{k t}+d_{0} \mathrm{CE}_{t-6}\right) \text { and } \\
& X_{t}^{*}=\left(b_{0}+b_{1} \bar{P}_{t}+b_{3} \mathrm{MINSTKTOT}_{t}\right) \mathrm{POP}_{t} e^{\beta t}
\end{aligned}
$$

Models (2) and (4):

$$
\begin{aligned}
& X_{t}-X_{t-6}=\left(\log X_{t}^{*}-\log X_{t-6}\right)\left(C_{0}+\sum_{k=2}^{12} \theta_{k} m_{k t}+d_{0} \mathrm{CE}_{t-6}\right) \text { and } \\
& \log X_{t}^{*}=b_{0}+b_{1} \log \bar{P}_{t}+b_{2} \log \mathrm{POP}_{t}+b_{3} \log \mathrm{MINSTKTOT}_{t}
\end{aligned}
$$

The $m_{k t}$ 's are a set of monthly dummies whose coefficients $\theta_{k}$ are not reported. Numbers in parentheses are $t$-statistics from heteroscedasticity-consistent standard errors. In models (1) and (3), the estimated long-run price elasticities of demand, computed at the point of means, are $-0.85(-4.65)$ and $-1.058(-5.126)$, respectively, for the period 1977-1993. For the period 1989-1993, the elasticities are $-1.07(-4.04)$ and $-1.68(-4.27)$, respectively. 
Table 5A. Brand Diffusion Models, One-Month Difference NOBS $=437$

\begin{tabular}{|c|c|c|c|c|}
\hline \multirow[b]{3}{*}{ Past Sales } & \multicolumn{2}{|c|}{ Endogenous $X_{t}^{*}$} & \multicolumn{2}{|c|}{ Exogenous $X_{t}^{*}$} \\
\hline & (1) & $(2)$ & (3) & $(4)$ \\
\hline & $\mathrm{XS}_{t-1}$ & $\log \left[\mathrm{XS}_{t-1}\right]$ & $\mathrm{XS}_{t-1}$ & $\log \left[\mathrm{XS}_{t-1}\right]$ \\
\hline$C_{\text {Tagamet }}$ & $\begin{array}{c}-0.3205 \\
(-0.71)\end{array}$ & $\begin{array}{c}5.0732 \\
(2.58)\end{array}$ & $\begin{array}{c}0.8032 \\
(1.38)\end{array}$ & $\begin{array}{c}2.5398 \\
(2.97)\end{array}$ \\
\hline$C_{\text {Zantac }}$ & $\begin{array}{c}2.0792 \\
(1.39)\end{array}$ & $\begin{array}{l}4.3498 \\
(1.75)\end{array}$ & $\begin{array}{c}-0.0310 \\
(-0.01)\end{array}$ & $\begin{array}{c}2.8082 \\
(3.33)\end{array}$ \\
\hline$C_{\text {Pepcid }}$ & $\begin{array}{c}4.5848 \\
(1.83)\end{array}$ & $\begin{array}{l}4.2097 \\
(1.48)\end{array}$ & $\begin{array}{c}-0.2280 \\
(-0.07)\end{array}$ & $\begin{array}{c}2.9241) \\
(3.21)\end{array}$ \\
\hline$C_{\text {Axid }}$ & $\begin{array}{c}5.8898 \\
(1.92)\end{array}$ & $\begin{array}{c}3.9249 \\
(1.53)\end{array}$ & $\begin{array}{c}0.0940 \\
(0.02)\end{array}$ & $\begin{array}{c}2.8447 \\
(3.16)\end{array}$ \\
\hline$d_{0}$ & $\begin{array}{c}-0.0032 \\
(-1.60)\end{array}$ & $\begin{array}{c}0.0218 \\
(0.05)\end{array}$ & $\begin{array}{c}0.0012 \\
(0.43)\end{array}$ & $\begin{array}{c}-0.5378 \\
(-3.74)\end{array}$ \\
\hline$d_{1}$ & $\begin{array}{c}0.0195 \\
(3.94)\end{array}$ & $\begin{array}{c}-0.2661 \\
(-0.75)\end{array}$ & $\begin{array}{c}0.0062 \\
(1.15)\end{array}$ & $\begin{array}{c}0.1343 \\
(1.83)\end{array}$ \\
\hline$b_{0}$ & $\begin{array}{c}-3.6129 \\
(-0.31)\end{array}$ & $\begin{array}{c}-149.32 \\
(-7.45)\end{array}$ & & \\
\hline$b_{1}$ & $\begin{array}{c}-0.1944 \\
(-0.30)\end{array}$ & $\begin{array}{c}-2.8627 \\
(-2.52)\end{array}$ & & \\
\hline$b_{2}$ & $\begin{array}{c}1.3485 \\
(0.63)\end{array}$ & $\begin{array}{c}28.2367 \\
(7.56)\end{array}$ & & \\
\hline$b_{3}$ & $\begin{array}{c}0.3502 \\
(3.43)\end{array}$ & $\begin{array}{c}-0.3003 \\
(-1.85)\end{array}$ & & \\
\hline$R^{2}$ & .194 & .179 & .146 & .061 \\
\hline
\end{tabular}

Table continues on following page. 


\section{Table 5A. Brand Diffusion Models, One-Month Difference (continued) NOBS $=437$}

\begin{tabular}{|c|c|c|c|c|}
\hline & \multicolumn{2}{|c|}{$\begin{array}{l}\text { Endogenous } X_{t}^{*} \\
(1)\end{array}$} & \multicolumn{2}{|c|}{ Exogenous $X_{t}^{*}$} \\
\hline$\epsilon_{P}$ (Tagamet) & $\begin{array}{c}-0.5149 \\
(-2.48)\end{array}$ & $\begin{array}{c}-1.2965 \\
(-3.80)\end{array}$ & $\begin{array}{c}-0.5721 \\
(-5.70)\end{array}$ & $\begin{array}{l}-1.6218 \\
(-2.70)\end{array}$ \\
\hline$\epsilon_{P}($ Zantac $)$ & $\begin{array}{c}-0.3980 \\
(-1.16)\end{array}$ & $\begin{array}{c}-1.7827 \\
(-3.01)\end{array}$ & $\begin{array}{c}-0.4992 \\
(-4.05)\end{array}$ & $\begin{array}{l}-2.3590 \\
(-2.23)\end{array}$ \\
\hline$\epsilon_{P}$ (Pepcid) & $\begin{array}{c}-0.5419 \\
(-4.44)\end{array}$ & $\begin{array}{c}-0.8878 \\
(-5.18)\end{array}$ & $\begin{array}{c}-0.5672 \\
(-6.17)\end{array}$ & $\begin{array}{r}-1.0320 \\
(-3.71)\end{array}$ \\
\hline$\epsilon_{P}($ Axid $)$ & $\begin{array}{c}-0.5875 \\
(-5.60)\end{array}$ & $\begin{array}{c}-0.7433 \\
(-6.30)\end{array}$ & $\begin{array}{c}-0.5989 \\
(-6.08)\end{array}$ & $\begin{array}{l}-0.8081 \\
(-5.25)\end{array}$ \\
\hline$\epsilon_{\mathrm{MIN}}$ (Tagamet) & $\begin{array}{l}1.3472 \\
(33.20)\end{array}$ & $\begin{array}{l}1.1659 \\
(21.72)\end{array}$ & $\begin{array}{l}1.2991 \\
(43.01)\end{array}$ & $\begin{array}{l}1.7863 \\
(7.44)\end{array}$ \\
\hline$\epsilon_{\mathrm{MIN}}($ Zantac $)$ & $\begin{array}{l}1.1475 \\
(27.08)\end{array}$ & $\begin{array}{l}0.9240 \\
(15.25)\end{array}$ & $\begin{array}{l}1.0881 \\
(41.76)\end{array}$ & $\begin{array}{l}1.6888 \\
(5.73)\end{array}$ \\
\hline$\epsilon_{\mathrm{MIN}}($ Pepcid $)$ & $\begin{array}{l}0.9904 \\
(35.69)\end{array}$ & $\begin{array}{l}0.8790 \\
(25.00)\end{array}$ & $\begin{array}{l}0.9608 \\
(43.29)\end{array}$ & $\begin{array}{l}1.2602 \\
(8.51)\end{array}$ \\
\hline$\epsilon_{\mathrm{MIN}}($ Axid $)$ & $\begin{array}{l}1.2944 \\
(36.67)\end{array}$ & $\begin{array}{l}1.1601 \\
(26.44)\end{array}$ & $\begin{array}{l}1.2588 \\
(43.37)\end{array}$ & $\begin{array}{l}1.6199 \\
(9.05)\end{array}$ \\
\hline
\end{tabular}

Note: In each model, the consumption externality is $\mathrm{CE}_{t}=\mathrm{XS}_{t}$ or $\log \left[\mathrm{XS}_{t}\right]$, and $\mathrm{CE}_{i t}=\mathrm{XS}_{i t}$ or $\log \left[\mathrm{XS}_{i t}\right]$. We estimate the following model by nonlinear least squares, using data for the four brands, combined to form an unbalanced panel:

$$
\Delta X_{i t}=\left[\log \left(\hat{s}_{i t}^{*} X_{t}^{*}\right)-\log X_{i t-1}\right] \cdot\left[C_{i}+\sum_{k=2}^{12} \theta_{k} m_{k t}+d_{0} \mathrm{CE}_{t-1}+d_{1} \mathrm{CE}_{i t-1}\right]
$$

The $\hat{s}_{i t}^{*}$ 's are the fitted equilibrium market shares from model (3) of Table 4, adjusted to account for the number of competing brands in each of the 4 epochs. The $m_{k t}$ 's are a set of monthly time dummies whose coefficients $\theta_{k}$ are not reported. In models (1) and (2), $\log X_{t}^{*}=b_{0}+b_{1} \log \bar{P}_{t}+b_{2} \log \mathrm{POP}_{t}+b_{3} \log \mathrm{MINSTKTOT}_{t}$. In models (3) and (4), we use the fitted values of $X_{t}^{*}$, taken from models (2) and (4), respectively, of Table 4A. Numbers in parentheses are $t$-statistics from heteroscedasticity-consistent standard errors. 
Table 5B. Brand Diffusion Models, Three-Month Difference

$$
\text { NOBS }=429
$$

\begin{tabular}{|c|c|c|c|c|}
\hline \multirow[b]{3}{*}{ Past Sales } & \multicolumn{2}{|c|}{ Endogenous $X_{t}^{*}$} & \multicolumn{2}{|c|}{ Exogenous $X_{t}^{*}$} \\
\hline & (1) & $(2)$ & $(3)$ & $(4)$ \\
\hline & $\mathrm{XS}_{t-3}$ & $\log \left[\mathrm{XS}_{t-3}\right]$ & $\mathrm{XS}_{t-3}$ & $\log \left[\mathrm{XS}_{t-3}\right]$ \\
\hline$C_{\text {Tagamet }}$ & $\begin{array}{r}0.5307 \\
(1.25)\end{array}$ & $\begin{array}{c}-2.6602 \\
(-1.76)\end{array}$ & $\begin{array}{l}1.3935 \\
(3.60)\end{array}$ & $\begin{array}{c}-1.5228 \\
(-1.12)\end{array}$ \\
\hline$C_{\text {Zantac }}$ & $\begin{array}{c}2.6309 \\
(1.46)\end{array}$ & $\begin{array}{c}-3.1004 \\
(-1.11)\end{array}$ & $\begin{array}{l}1.2637 \\
(0.52)\end{array}$ & $\begin{array}{c}-1.4328 \\
(-0.50)\end{array}$ \\
\hline$C_{\text {Pepcid }}$ & $\begin{array}{l}4.2109 \\
(1.46)\end{array}$ & $\begin{array}{c}-2.0477 \\
(-0.68)\end{array}$ & $\begin{array}{c}0.7658 \\
(0.20)\end{array}$ & $\begin{array}{c}-0.3996 \\
(-0.13)\end{array}$ \\
\hline$C_{\text {Axid }}$ & $\begin{array}{c}5.1534 \\
(1.50)\end{array}$ & $\begin{array}{c}-3.9436 \\
(-1.35)\end{array}$ & $\begin{array}{l}1.2937 \\
(0.28)\end{array}$ & $\begin{array}{c}-2.4764 \\
(-0.84)\end{array}$ \\
\hline$d_{0}$ & $\begin{array}{c}-0.0024 \\
(-1.04)\end{array}$ & $\begin{array}{c}0.0612 \\
(0.13)\end{array}$ & $\begin{array}{c}.4395 \times 10^{-3} \\
(0.14)\end{array}$ & $\begin{array}{c}-0.2576 \\
(-0.52)\end{array}$ \\
\hline$d_{1}$ & $\begin{array}{c}0.0180 \\
(4.04)\end{array}$ & $\begin{array}{l}1.3585 \\
(4.57)\end{array}$ & $\begin{array}{c}0.0082 \\
(1.60)\end{array}$ & $\begin{array}{l}1.4884 \\
(5.49)\end{array}$ \\
\hline$b_{0}$ & $\begin{array}{c}-26.887 \\
(-2.41)\end{array}$ & $\begin{array}{c}-49.474 \\
(-3.05)\end{array}$ & & \\
\hline$b_{1}$ & $\begin{array}{c}-1.0205 \\
(-1.59)\end{array}$ & $\begin{array}{c}-1.2366 \\
(-1.26)\end{array}$ & & \\
\hline$b_{2}$ & $\begin{array}{l}5.7040 \\
(2.73)\end{array}$ & $\begin{array}{l}9.8617 \\
(3.25)\end{array}$ & & \\
\hline$b_{3}$ & $\begin{array}{c}0.2182 \\
(2.92)\end{array}$ & $\begin{array}{c}0.1069 \\
(0.87)\end{array}$ & & \\
\hline$R^{2}$ & .293 & .200 & .227 & .176 \\
\hline
\end{tabular}

Table continues on following page. 


\section{Table 5B. Brand Diffusion Models, Three-Month Difference (continued) NOBS $=429$}

\begin{tabular}{|c|c|c|c|c|}
\hline & \multicolumn{2}{|c|}{$\begin{array}{lc}\text { Endogenous } & X_{t}^{*} \\
(1) & (2)\end{array}$} & \multicolumn{2}{|c|}{ Exogenous $X_{t}^{*}$} \\
\hline$\epsilon_{P}$ (Tagamet) & $\begin{array}{c}-0.7569 \\
(-3.73)\end{array}$ & $\begin{array}{l}-0.8202 \\
(-2.76)\end{array}$ & $\begin{array}{c}-0.6436 \\
(-5.90)\end{array}$ & $\begin{array}{c}-0.5103 \\
(-2.97)\end{array}$ \\
\hline$\epsilon_{P}($ Zantac $)$ & $\begin{array}{c}-0.8266 \\
(-2.46)\end{array}$ & $\begin{array}{c}-0.9388 \\
(-1.84)\end{array}$ & $\begin{array}{c}-0.6259 \\
(-4.32)\end{array}$ & $\begin{array}{r}-0.3897 \\
(-1.41)\end{array}$ \\
\hline$\epsilon_{P}$ (Pepcid) & $\begin{array}{c}-0.6490 \\
(-5.38)\end{array}$ & $\begin{array}{c}-0.6770 \\
(-4.39)\end{array}$ & $\begin{array}{c}-0.5988 \\
(-6.37)\end{array}$ & $\begin{array}{l}-0.5398 \\
(-4.87)\end{array}$ \\
\hline$\epsilon_{P}($ Axid $)$ & $\begin{array}{c}-0.6357 \\
(-6.08)\end{array}$ & $\begin{array}{c}-0.6483 \\
(-5.73)\end{array}$ & $\begin{array}{c}-0.6131 \\
(-6.20)\end{array}$ & $\begin{array}{c}-0.5866 \\
(-5.73)\end{array}$ \\
\hline$\epsilon_{\mathrm{MIN}}$ (Tagamet) & $\begin{array}{l}1.3104 \\
(36.74)\end{array}$ & $\begin{array}{l}1.2794 \\
(28.45)\end{array}$ & $\begin{array}{l}1.2925 \\
(42.17)\end{array}$ & $\begin{array}{l}1.2946 \\
(33.05)\end{array}$ \\
\hline$\epsilon_{\mathrm{MIN}}($ Zantac $)$ & $\begin{array}{l}1.1021 \\
(31.48)\end{array}$ & $\begin{array}{l}1.0639 \\
(21.87)\end{array}$ & $\begin{array}{l}1.0800 \\
(40.04)\end{array}$ & $\begin{array}{l}1.0826 \\
(26.87)\end{array}$ \\
\hline$\epsilon_{\mathrm{MIN}}($ Pepcid $)$ & $\begin{array}{l}0.9677 \\
(38.60)\end{array}$ & $\begin{array}{l}0.9487 \\
(31.42)\end{array}$ & $\begin{array}{l}0.9567 \\
(42.66)\end{array}$ & $\begin{array}{l}0.9580 \\
(35.52)\end{array}$ \\
\hline$\epsilon_{\mathrm{MIN}}($ Axid $)$ & $\begin{array}{l}1.2672 \\
(39.29)\end{array}$ & $\begin{array}{l}1.2442 \\
(32.65)\end{array}$ & $\begin{array}{l}1.2539 \\
(42.82)\end{array}$ & $\begin{array}{l}1.2555 \\
(36.47)\end{array}$ \\
\hline
\end{tabular}

Note: In each model, the consumption externality is $\mathrm{CE}_{t}=\mathrm{XS}_{t}$ or $\log \left[\mathrm{XS}_{t}\right]$, and $\mathrm{CE}_{i t}=\mathrm{XS}_{i t}$ or $\log \left[\mathrm{XS}_{i t}\right]$. We estimate the following model by nonlinear least squares, using data for the four brands, combined to form an unbalanced panel:

$$
X_{i t}-X_{i t-3}=\left[\log \left(\hat{s}_{i t}^{*} X_{t}^{*}\right)-\log X_{i t-3}\right] \cdot\left[C_{i}+\sum_{k=2}^{12} \theta_{k} m_{k t}+d_{0} \mathrm{CE}_{t-3}+d_{1} \mathrm{CE}_{i t-3}\right]
$$

The $\hat{s}_{i t}^{*}$ 's are the fitted equilibrium market shares from model (3) of Table 4, adjusted to account for the number of competing brands in each of the 4 epochs. The $m_{k t}$ 's are a set of monthly time dummies whose coefficients $\theta_{k}$ are not reported. In models (1) and (2), $\log X_{t}^{*}=b_{0}+b_{1} \log \bar{P}_{t}+b_{2} \log \mathrm{POP}_{t}+b_{3} \log \mathrm{MINSTKTOT}_{t}$. In models (3) and (4), we use the fitted values of $X_{t}^{*}$, taken from models (2) and (4), respectively, of Table 4B. Numbers in parentheses are $t$-statistics from heteroscedasticity-consistent standard errors. 
Table 5C. Brand Diffusion Models, Six-Month Difference $\mathrm{NOBS}=417$

\begin{tabular}{|c|c|c|c|c|}
\hline \multirow[b]{3}{*}{ Past Sales } & \multicolumn{2}{|c|}{ Endogenous $X_{t}^{*}$} & \multicolumn{2}{|c|}{ Exogenous $X_{t}^{*}$} \\
\hline & (1) & $(2)$ & (3) & $(4)$ \\
\hline & $\mathrm{XS}_{t-6}$ & $\log \left[\mathrm{XS}_{t-6}\right]$ & $\mathrm{XS}_{t-6}$ & $\log \left[\mathrm{XS}_{t-6}\right]$ \\
\hline$C_{\text {Tagamet }}$ & $\begin{array}{c}0.2271 \\
(0.44)\end{array}$ & $\begin{array}{c}-4.4561 \\
(-2.62)\end{array}$ & $\begin{array}{l}1.8403 \\
(2.54)\end{array}$ & $\begin{array}{c}-2.1413 \\
(-1.50)\end{array}$ \\
\hline$C_{\text {Zantac }}$ & $\begin{array}{c}-0.5319 \\
(-0.18)\end{array}$ & $\begin{array}{c}-3.3487 \\
(-1.13)\end{array}$ & $\begin{array}{c}0.0606 \\
(0.02)\end{array}$ & $\begin{array}{c}-1.4171 \\
(-0.54)\end{array}$ \\
\hline$C_{\text {Pepcid }}$ & $\begin{array}{c}-0.9357 \\
(-0.21)\end{array}$ & $\begin{array}{c}-1.8496 \\
(-0.58)\end{array}$ & $\begin{array}{c}-1.8995 \\
(-0.39)\end{array}$ & $\begin{array}{c}-0.8102 \\
(-0.29)\end{array}$ \\
\hline$C_{\text {Axid }}$ & $\begin{array}{c}-1.3683 \\
(-0.25)\end{array}$ & $\begin{array}{c}-5.5432 \\
(-1.79)\end{array}$ & $\begin{array}{c}-2.6523 \\
(-0.45)\end{array}$ & $\begin{array}{c}-3.9959 \\
(-1.49)\end{array}$ \\
\hline$d_{0}$ & $\begin{array}{c}0.0016 \\
(0.44)\end{array}$ & $\begin{array}{c}-0.4136 \\
(-0.84)\end{array}$ & $\begin{array}{r}0.0027 \\
(0.70)\end{array}$ & $\begin{array}{c}-0.5692 \\
(-1.31)\end{array}$ \\
\hline$d_{1}$ & $\begin{array}{r}0.0177 \\
(3.91)\end{array}$ & $\begin{array}{l}2.1887 \\
(6.49)\end{array}$ & $\begin{array}{c}0.0084 \\
(1.65)\end{array}$ & $\begin{array}{c}8.1700 \\
(4.47)\end{array}$ \\
\hline$b_{0}$ & $\begin{array}{c}-36.034 \\
(-4.32)\end{array}$ & $\begin{array}{c}-56.393 \\
(-4.17)\end{array}$ & & \\
\hline$b_{1}$ & $\begin{array}{c}-1.2528 \\
(-2.60)\end{array}$ & $\begin{array}{c}-1.1395 \\
(-1.60)\end{array}$ & & \\
\hline$b_{2}$ & $\begin{array}{c}7.4182 \\
(4.74)\end{array}$ & $\begin{array}{l}11.145 \\
(4.40)\end{array}$ & & \\
\hline$b_{3}$ & $\begin{array}{c}0.1296 \\
(2.31)\end{array}$ & $\begin{array}{c}0.0062 \\
(0.06)\end{array}$ & & \\
\hline$R^{2}$ & .472 & .361 & .382 & .318 \\
\hline
\end{tabular}

Table continues on following page. 


\section{Table 5C. Brand Diffusion Models, Six-Month Difference (continued) NOBS $=417$}

\begin{tabular}{|c|c|c|c|c|}
\hline & \multicolumn{2}{|c|}{$\begin{array}{ll}\text { Endogenous } & X_{t}^{*} \\
(1) & (2)\end{array}$} & \multicolumn{2}{|c|}{ Exogenous $X_{t}^{*}$} \\
\hline$\epsilon_{P}$ (Tagamet) & $\begin{array}{c}-0.8250 \\
(-5.13)\end{array}$ & $\begin{array}{c}-0.7918 \\
(-3.56)\end{array}$ & $\begin{array}{c}-0.6575 \\
(-6.25)\end{array}$ & $\begin{array}{c}-0.5579 \\
(-3.24)\end{array}$ \\
\hline$\epsilon_{P}($ Zantac $)$ & $\begin{array}{c}-0.9472 \\
(-3.71)\end{array}$ & $\begin{array}{c}-0.8884 \\
(-2.38)\end{array}$ & $\begin{array}{c}-0.6506 \\
(-4.81)\end{array}$ & $\begin{array}{c}-0.4741 \\
(-1.71)\end{array}$ \\
\hline$\epsilon_{P}$ (Pepcid) & $\begin{array}{c}-0.6791 \\
(-6.31)\end{array}$ & $\begin{array}{c}-0.6644 \\
(-5.23)\end{array}$ & $\begin{array}{c}-0.6050 \\
(-6.50)\end{array}$ & $\begin{array}{l}-0.5609 \\
(-5.06)\end{array}$ \\
\hline$\epsilon_{P}($ Axid $)$ & $\begin{array}{c}-0.6493 \\
(-6.39)\end{array}$ & $\begin{array}{l}-0.6427 \\
(-6.05)\end{array}$ & $\begin{array}{c}-0.6159 \\
(-6.24)\end{array}$ & $\begin{array}{c}-0.5961 \\
(-5.82)\end{array}$ \\
\hline$\epsilon_{\mathrm{MIN}}$ (Tagamet) & $\begin{array}{l}1.2857 \\
(39.06)\end{array}$ & $\begin{array}{l}1.2513 \\
(31.54)\end{array}$ & $\begin{array}{l}1.2887 \\
(42.36)\end{array}$ & $\begin{array}{l}1.2830 \\
(32.99)\end{array}$ \\
\hline$\epsilon_{\mathrm{MIN}}($ Zantac $)$ & $\begin{array}{l}1.0717 \\
(34.97)\end{array}$ & $\begin{array}{l}1.0293 \\
(25.08)\end{array}$ & $\begin{array}{l}1.0754 \\
(40.67)\end{array}$ & $\begin{array}{l}1.0683 \\
(26.78)\end{array}$ \\
\hline$\epsilon_{\mathrm{MIN}}($ Pepcid $)$ & $\begin{array}{l}0.9526 \\
(40.35)\end{array}$ & $\begin{array}{l}0.9314 \\
(34.18)\end{array}$ & $\begin{array}{l}0.9544 \\
(42.78)\end{array}$ & $\begin{array}{l}0.9509 \\
(35.45)\end{array}$ \\
\hline$\epsilon_{\mathrm{MIN}}($ Axid $)$ & $\begin{array}{l}1.2489 \\
(40.81)\end{array}$ & $\begin{array}{l}1.2234 \\
(35.23)\end{array}$ & $\begin{array}{l}1.2511 \\
(42.92)\end{array}$ & $\begin{array}{l}1.2468 \\
(36.42)\end{array}$ \\
\hline
\end{tabular}

Note: In each model, the consumption externality is $\mathrm{CE}_{t}=\mathrm{XS}_{t}$ or $\log \left[\mathrm{XS}_{t}\right]$, and $\mathrm{CE}_{i t}=\mathrm{XS}_{i t}$ or $\log \left[\mathrm{XS}_{i t}\right]$. We estimate the following model by nonlinear least squares, using data for the four brands, combined to form an unbalanced panel:

$$
X_{i t}-X_{i t-6}=\left[\log \left(\hat{s}_{i t}^{*} X_{t}^{*}\right)-\log X_{i t-6}\right] \cdot\left[C_{i}+\sum_{k=2}^{12} \theta_{k} m_{k t}+d_{0} \mathrm{CE}_{t-6}+d_{1} \mathrm{CE}_{i t-6}\right]
$$

The $\hat{s}_{i t}^{*}$ 's are the fitted equilibrium market shares from model (3) of Table 4, adjusted to account for the number of competing brands in each of the 4 epochs. The $m_{k t}$ 's are a set of monthly time dummies whose coefficients $\theta_{k}$ are not reported. In models (1) and (2), $\log X_{t}^{*}=b_{0}+b_{1} \log \bar{P}_{t}+b_{2} \log \mathrm{POP}_{t}+b_{3} \log$ MINSTKTOT $_{t}$. In models (3) and (4), we use the fitted values of $X_{t}^{*}$, taken from models (2) and (4), respectively, of Table 4C. Numbers in parentheses are $t$-statistics from heteroscedasticity-consistent standard errors. 


\section{Table 6. Simulation Diagnostics}

\begin{tabular}{|c|c|c|c|c|c|}
\hline & \multirow{2}{*}{$\begin{array}{c}\text { Industry Model } \\
\text { Model (2) Table 4B } \\
\text { Total Industry Demand }\end{array}$} & \multicolumn{4}{|c|}{$\begin{array}{c}\text { Brand Model } \\
\text { Model (1) Table 5B }\end{array}$} \\
\hline & & Tagamet & Zantac & Pepcid & Axid \\
\hline Root-Mean-Squared Error: & 4.5166 & 3.7626 & 2.1634 & 0.9159 & 1.6475 \\
\hline Mean Absolute Error: & 3.4844 & 2.9771 & 1.7691 & 0.7492 & 1.4644 \\
\hline Mean Error: & 0.0188 & -1.1496 & -0.4500 & 0.4040 & 1.4644 \\
\hline $\begin{array}{l}\text { Regression coefficient of } \\
\text { actual on predicted: }\end{array}$ & 1.0147 & 0.9690 & 1.0529 & 1.1962 & 1.3935 \\
\hline Theil's Inequality Coefficient: & 0.0380 & 0.0622 & 0.0306 & 0.0442 & 0.1576 \\
\hline Fraction of Error due to Bias: & 0.0000 & 0.0933 & 0.0433 & 0.1945 & 0.7901 \\
\hline $\begin{array}{l}\text { Fraction of Error due to } \\
\text { Different Variation: }\end{array}$ & 0.0289 & 0.0289 & 0.1311 & 0.3645 & 0.1332 \\
\hline $\begin{array}{l}\text { Fraction of Error due to } \\
\text { Difference Covariation: }\end{array}$ & 0.9710 & 0.8777 & 0.8257 & 0.4410 & 0.0767 \\
\hline
\end{tabular}

Note: The Root-Mean-Squared Error (RMS) for the variable $X_{i t}$ is defined as

$$
\operatorname{RMS}=\sqrt{\frac{1}{T} \sum_{t=1}^{T}\left(X_{i t}^{\operatorname{sim}}-X_{i t}^{\text {actual }}\right)^{2}}
$$

Also shown is Theil's inequality coefficient, which is defined as

$$
U=\frac{\mathrm{RMS}}{\sqrt{\frac{1}{T} \sum_{t=1}^{T}\left(X_{i t}^{\text {sim }}\right)^{2}}+\sqrt{\frac{1}{T} \sum_{t=1}^{T}\left(X_{i t}^{\text {actual }}\right)^{2}}}
$$

where $X_{i t}^{\text {sim }}=$ simulated value of $X_{i t}, X_{i t}^{\text {actual }}=$ actual value, and $T=$ number of months for the simulation. $U$ measures RMS in relative terms. The Theil inequality coefficient can be decomposed into bias, variance, and covariance as displayed in the table. For more on simulation diagnostics, see Pindyck and Rubinfeld (1997), pp. 710-712. 


\section{Table 7. Simulation Experiments}

\begin{tabular}{|c|c|c|c|c|c|c|}
\hline \multirow[b]{2}{*}{ Experiment } & \multicolumn{4}{|c|}{ May 1993} & \multirow[b]{2}{*}{$\Delta \Sigma \Pi_{T}$} & \multirow[b]{2}{*}{$\Delta \Sigma \Pi_{Z}$} \\
\hline & $\Delta X_{T}$ & $\Delta X_{Z}$ & $\Delta X_{P}$ & $\Delta X_{A}$ & & \\
\hline \multicolumn{7}{|l|}{ (1) } \\
\hline Zantac Price at & 1.5733 & 10.784 & 0.7073 & 0.1710 & 268.21 & -669.6 \\
\hline Tagamet Level & $6.87 \%$ & $22.3 \%$ & $5.05 \%$ & $2.79 \%$ & $5.07 \%$ & $-0.11 \%$ \\
\hline \multicolumn{7}{|l|}{$(2)$} \\
\hline Zantac Advertising & 5.8974 & -13.548 & 2.9091 & 1.0013 & 306.54 & -662.2 \\
\hline at Tagamet Level & $26.0 \%$ & $-27.88 \%$ & $22.34 \%$ & $16.25 \%$ & $5.79 \%$ & $-10.7 \%$ \\
\hline \multicolumn{7}{|l|}{$(3)$} \\
\hline Zantac Advertising & 4.3938 & -19.643 & 2.2330 & 0.8278 & 150.98 & -1626.8 \\
\hline $\begin{array}{l}\text { and Attributes at } \\
\text { Tagamet Level }\end{array}$ & $19.4 \%$ & $-40.5 \%$ & $17.1 \%$ & $13.4 \%$ & $2.85 \%$ & $-26.4 \%$ \\
\hline \multicolumn{7}{|l|}{$(4)$} \\
\hline Coefficient $d_{1}$ & 3.5294 & -3.5837 & -1.6551 & -3.1595 & -106.12 & -882.3 \\
\hline Reduced by $50 \%$ & $15.7 \%$ & $-7.39 \%$ & $-12.8 \%$ & $-52.9 \%$ & $-2.02 \%$ & $-14.4 \%$ \\
\hline
\end{tabular}

Note: $\Delta X_{Z}$ is difference in Zantac sales between the experiment and the base case, in May 1993. Similarly, $\Delta X_{T}, \Delta X_{P}$, and $\Delta X_{A}$ are the differences in Tagamet, Pepcid, and Axid sales in May 1993. $\Delta \Sigma \Pi_{Z}$ is the aggregate change in gross profit for Zantac under the simulation experiment compared to the base case simulation. Likewise, $\Delta \Sigma \Pi_{T}$ is the aggregate change in gross profit for Tagamet. The first number in each row is the absolute change (in millions of patient days or millions of dollars) and the second number is the percentage change. In Experiments (2) and (3), we use an average cost per minute of detailing, which varies from $\$ 3.76$ in 1983 to $\$ 8.09$ in 1993 , to calculate the savings in reduced advertising expenditures for Zantac. 


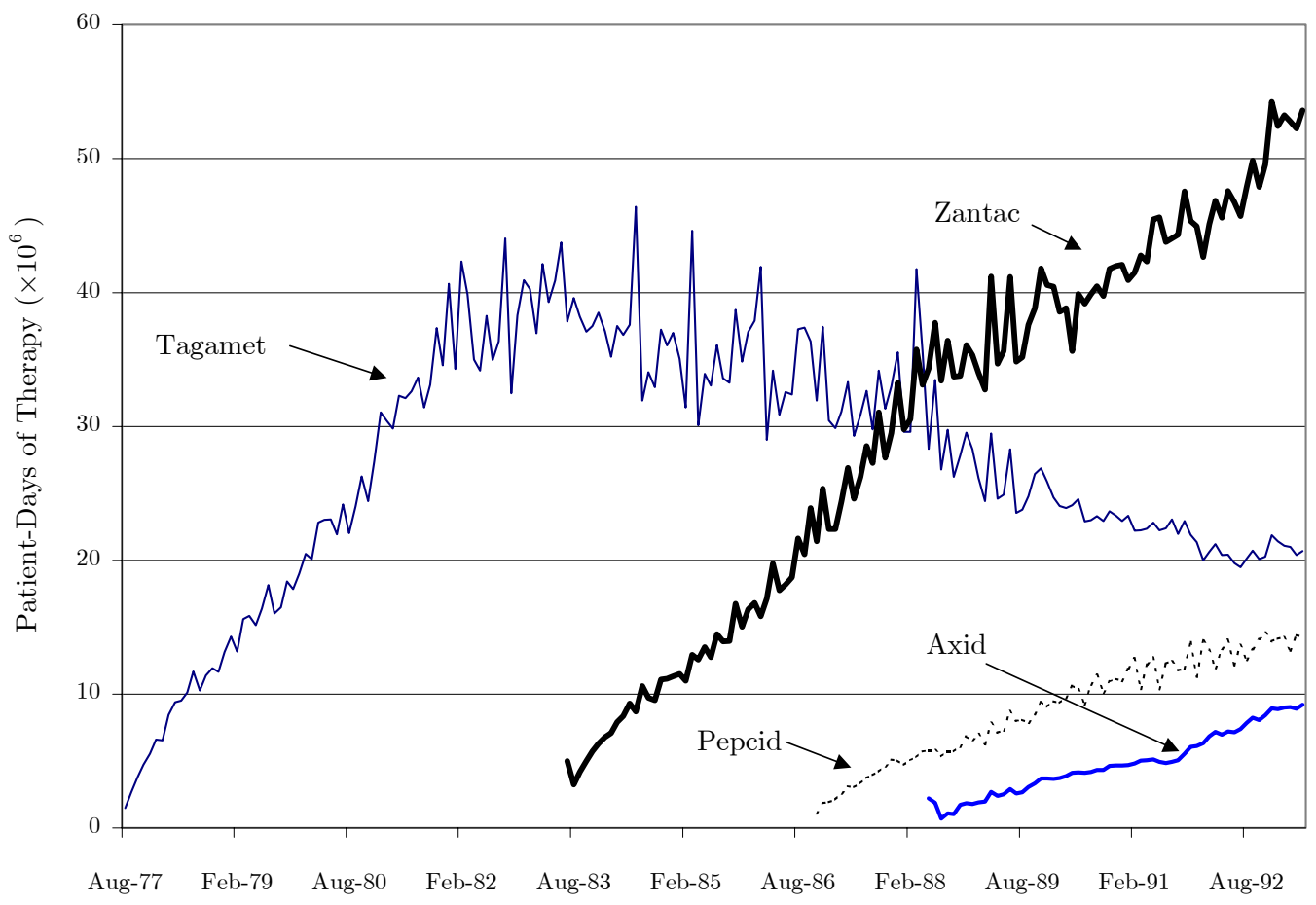

Figure 1: Monthly Sales of $\mathbf{H}_{2}$-Antagonist Drugs

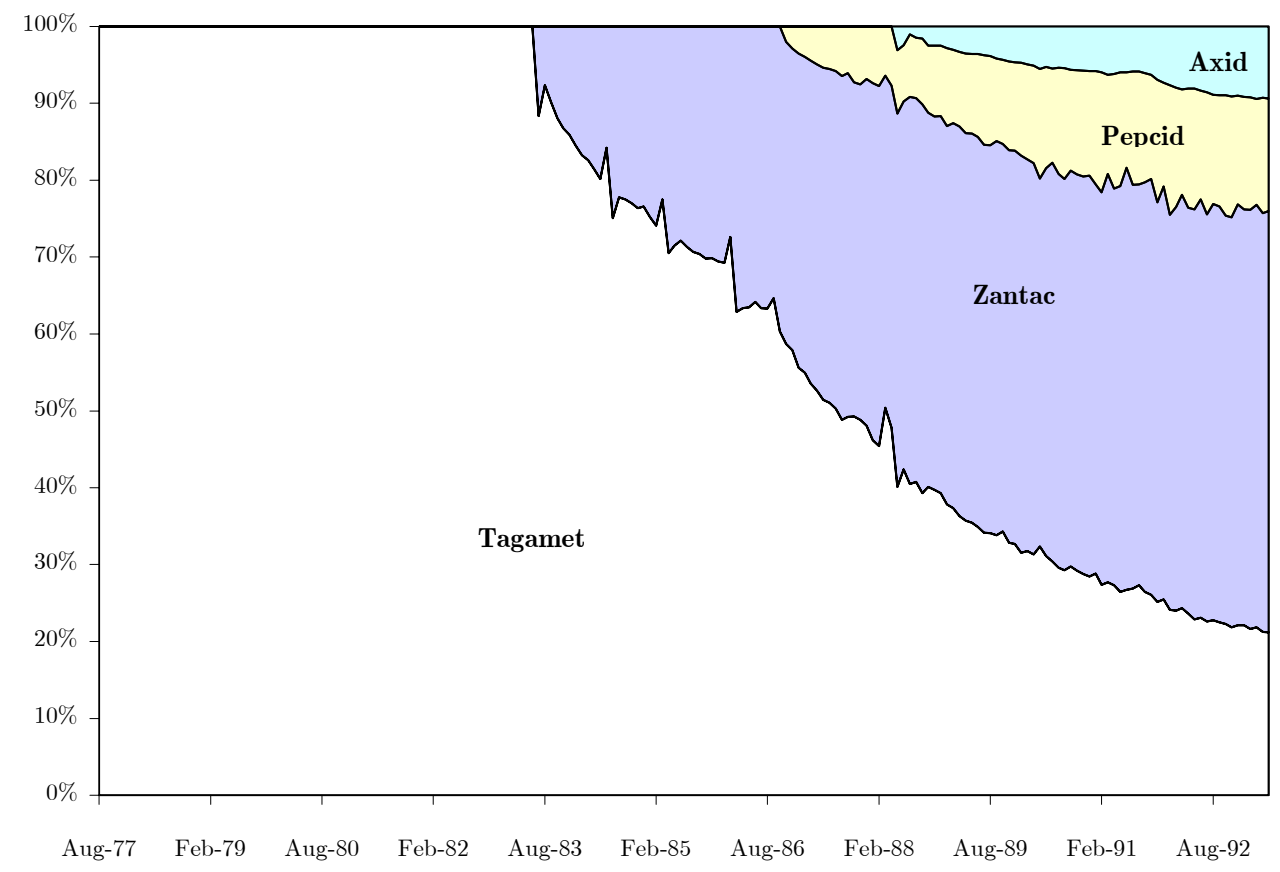

Figure 2: Market Shares of $\mathrm{H}_{2}$-Antagonist Drugs 


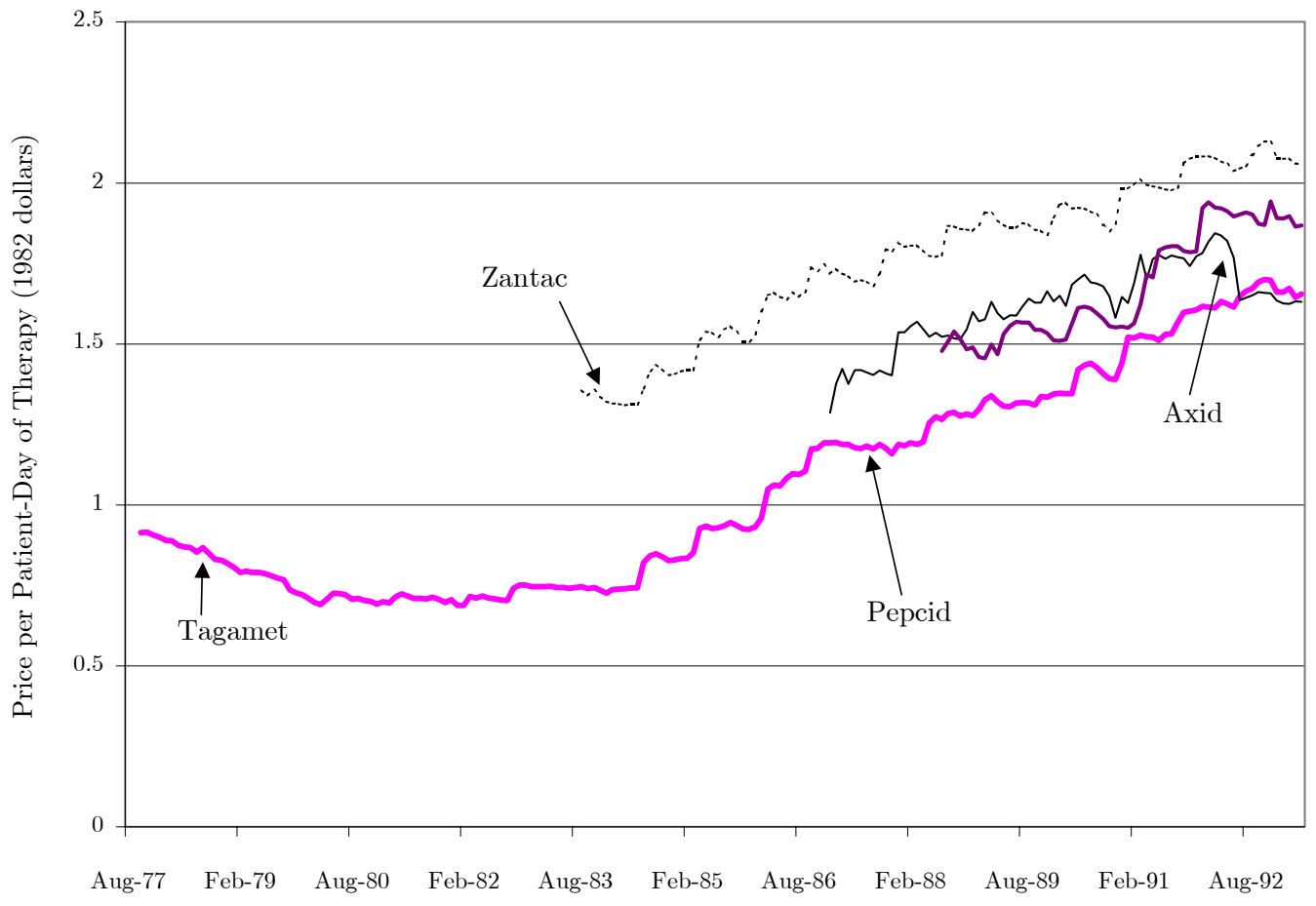

Figure 3: Real Prices of $\mathbf{H}_{2}$-Antagonist Drugs

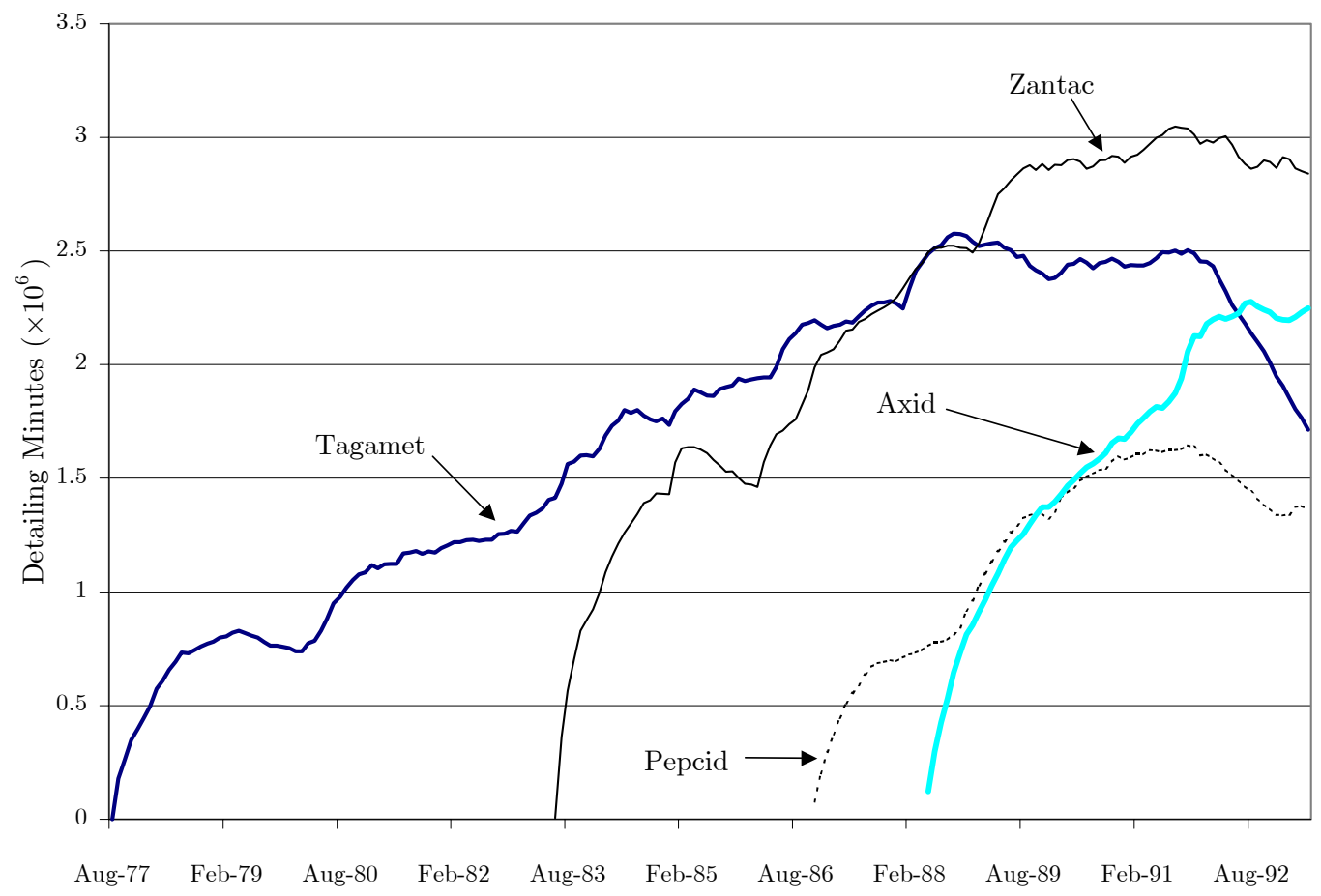

Figure 4: Depreciated Stocks of Detailing Minutes $(\delta=5 \%)$ 


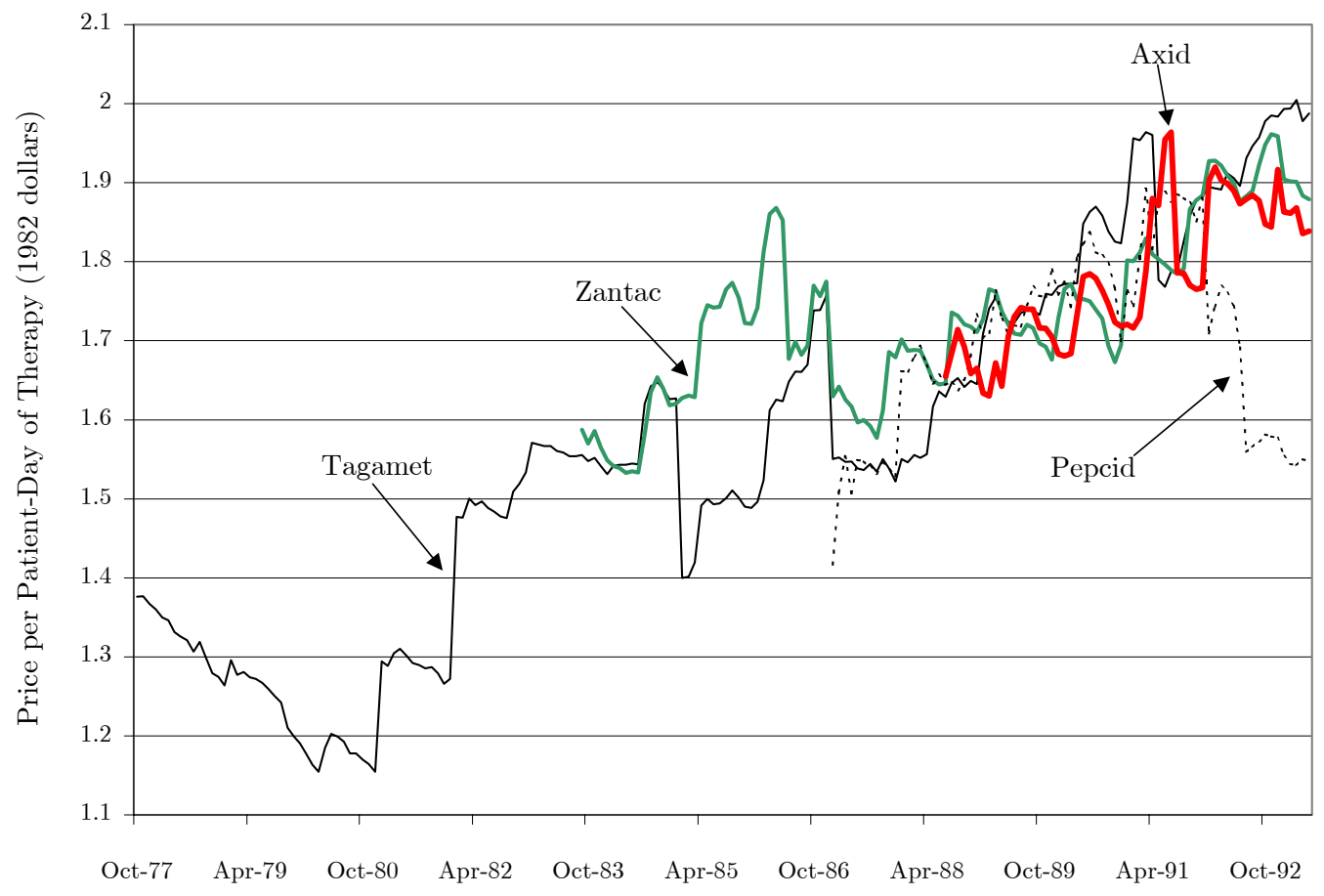

Figure 5: Quality-Adjusted Real Prices of $\mathbf{H}_{2}$-Antagonist Drugs

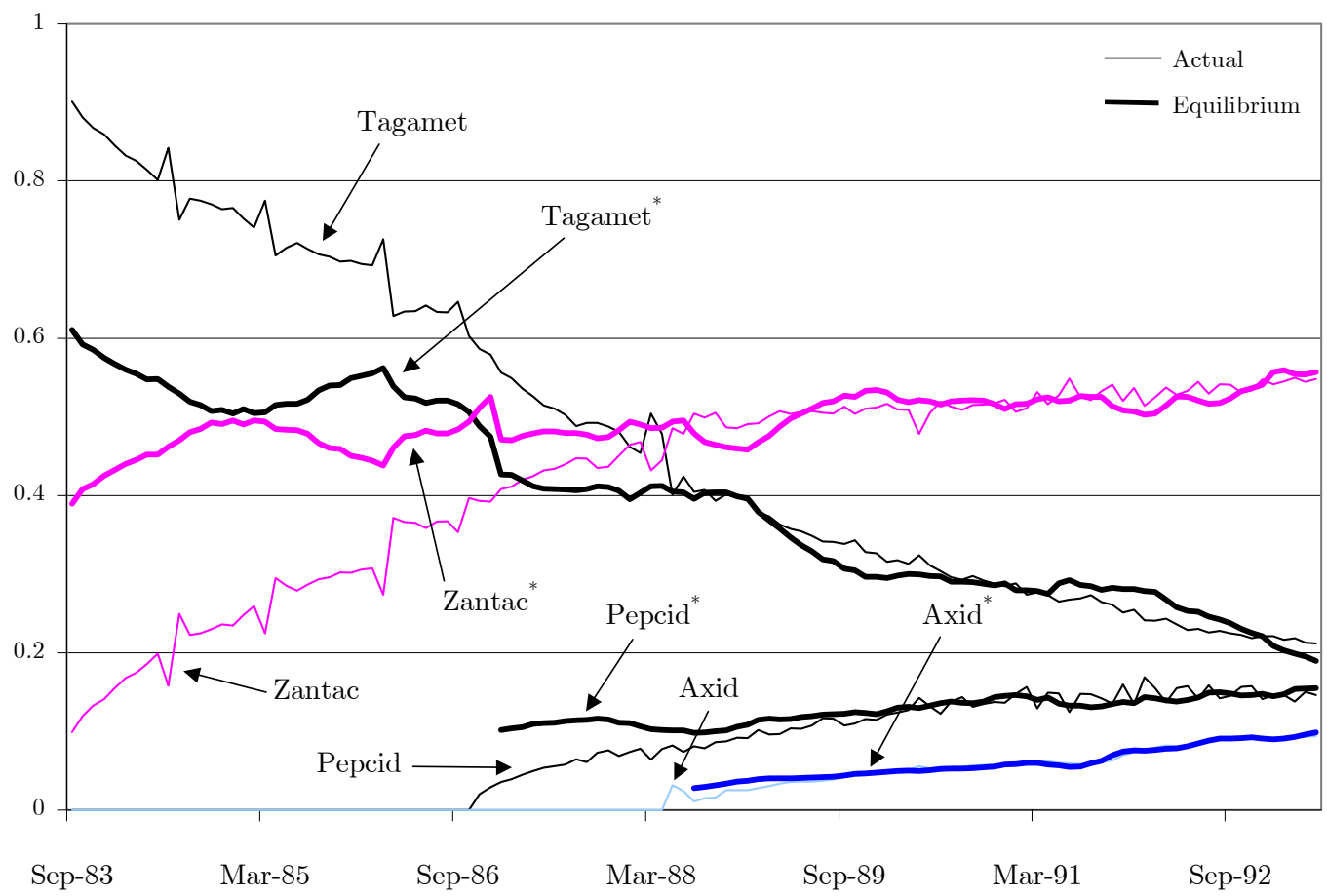

Figure 6: Actual and Fitted Equilibrium Brand Shares 


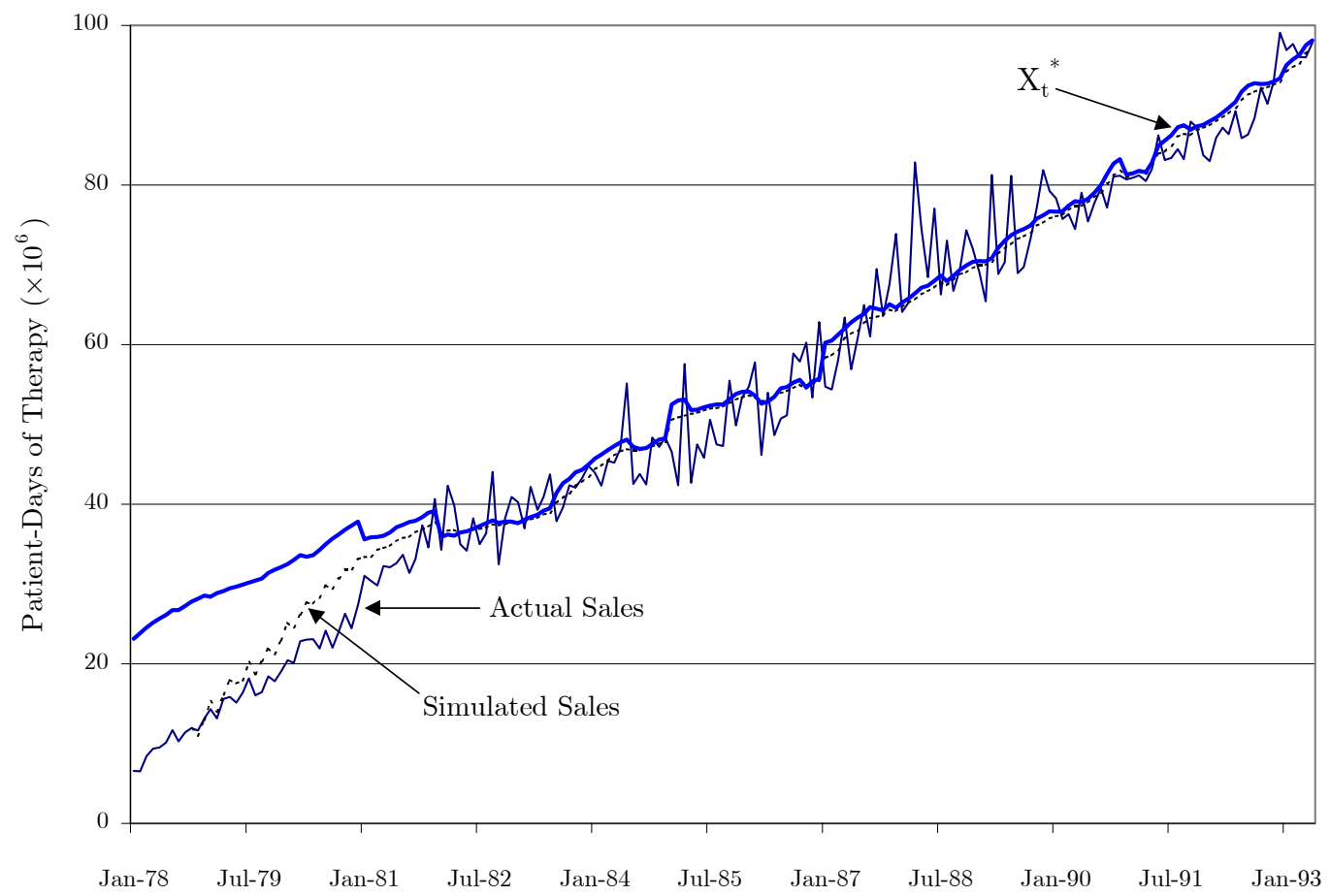

Figure 7: Simulation of industry-Level Diffusion Model [Uses Table 4B, Model (2)]

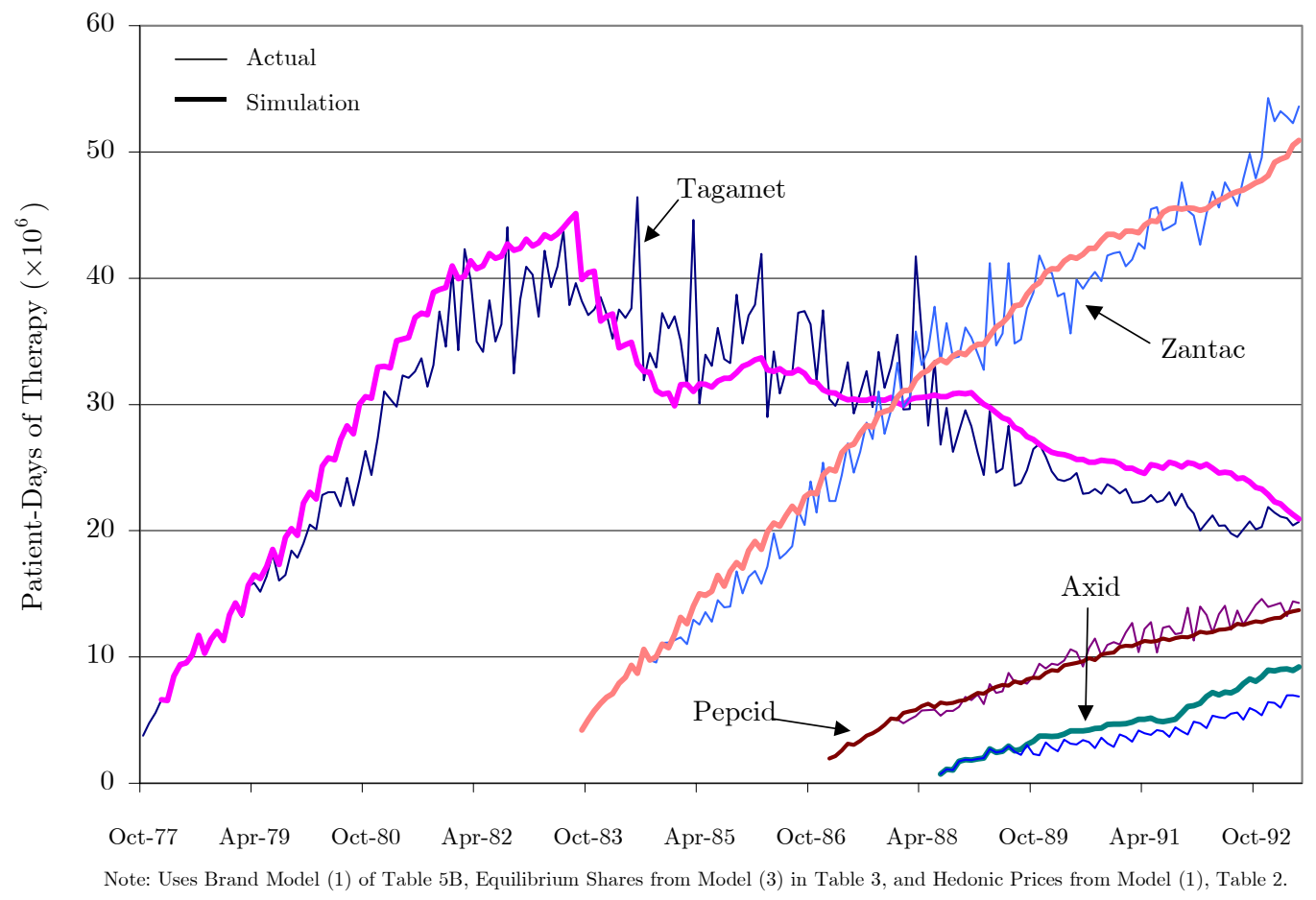

Figure 8: Full Model Simulation of Brand Sales versus Actual 


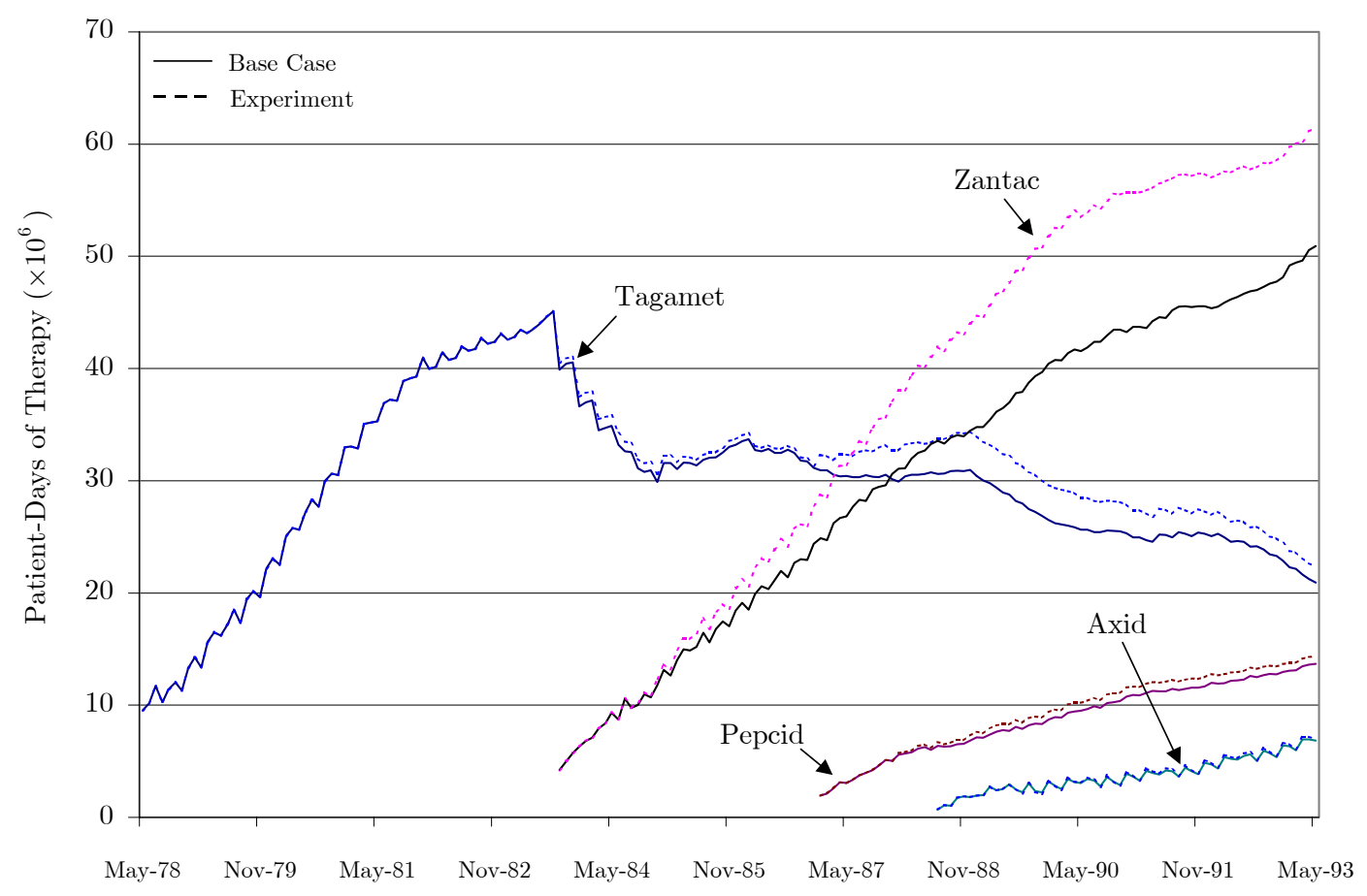

Figure 9: Zantac Price Set Equal to Tagamet's

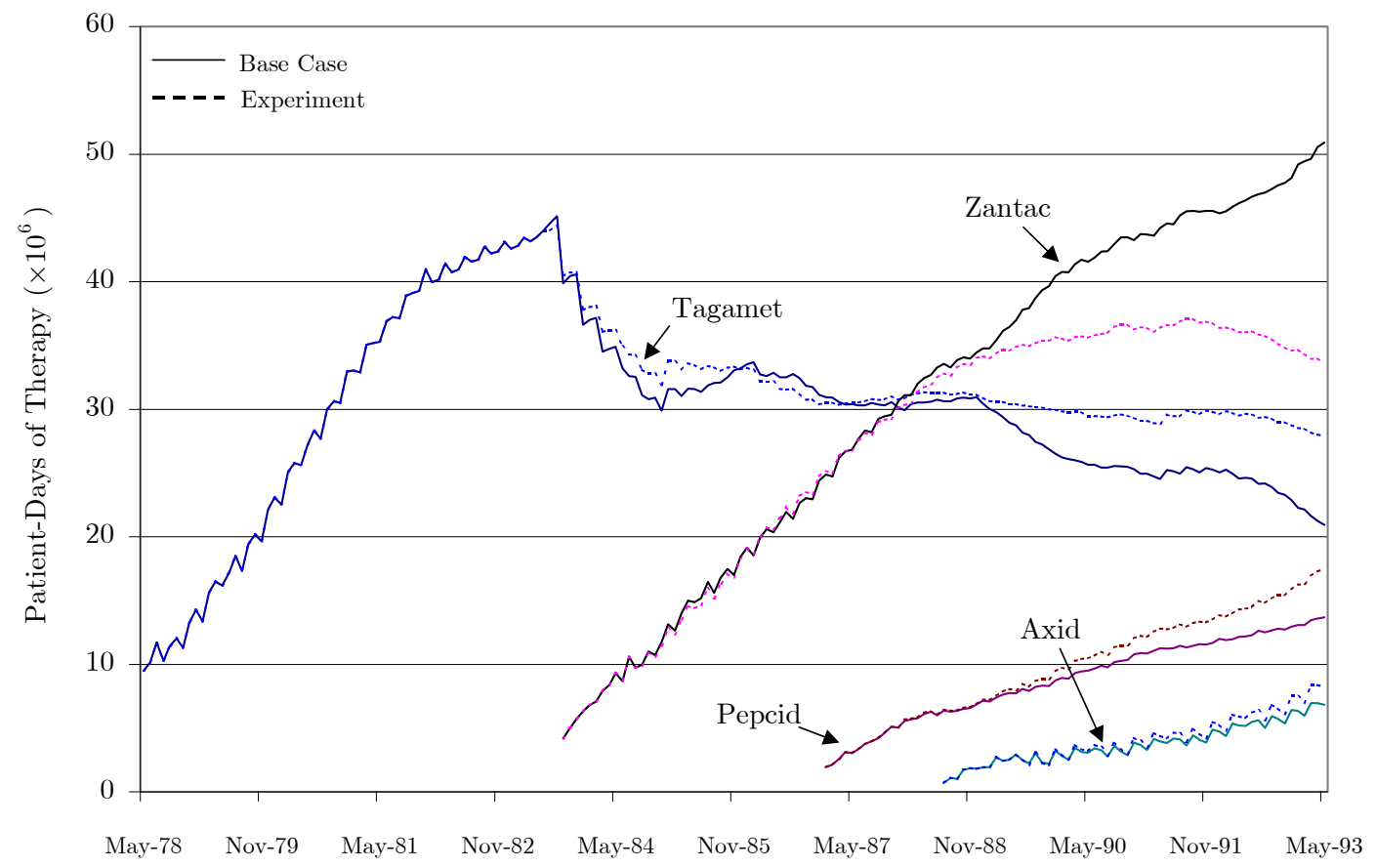

Figure 10: Zantac Detailing Set Equal to Tagamet's 


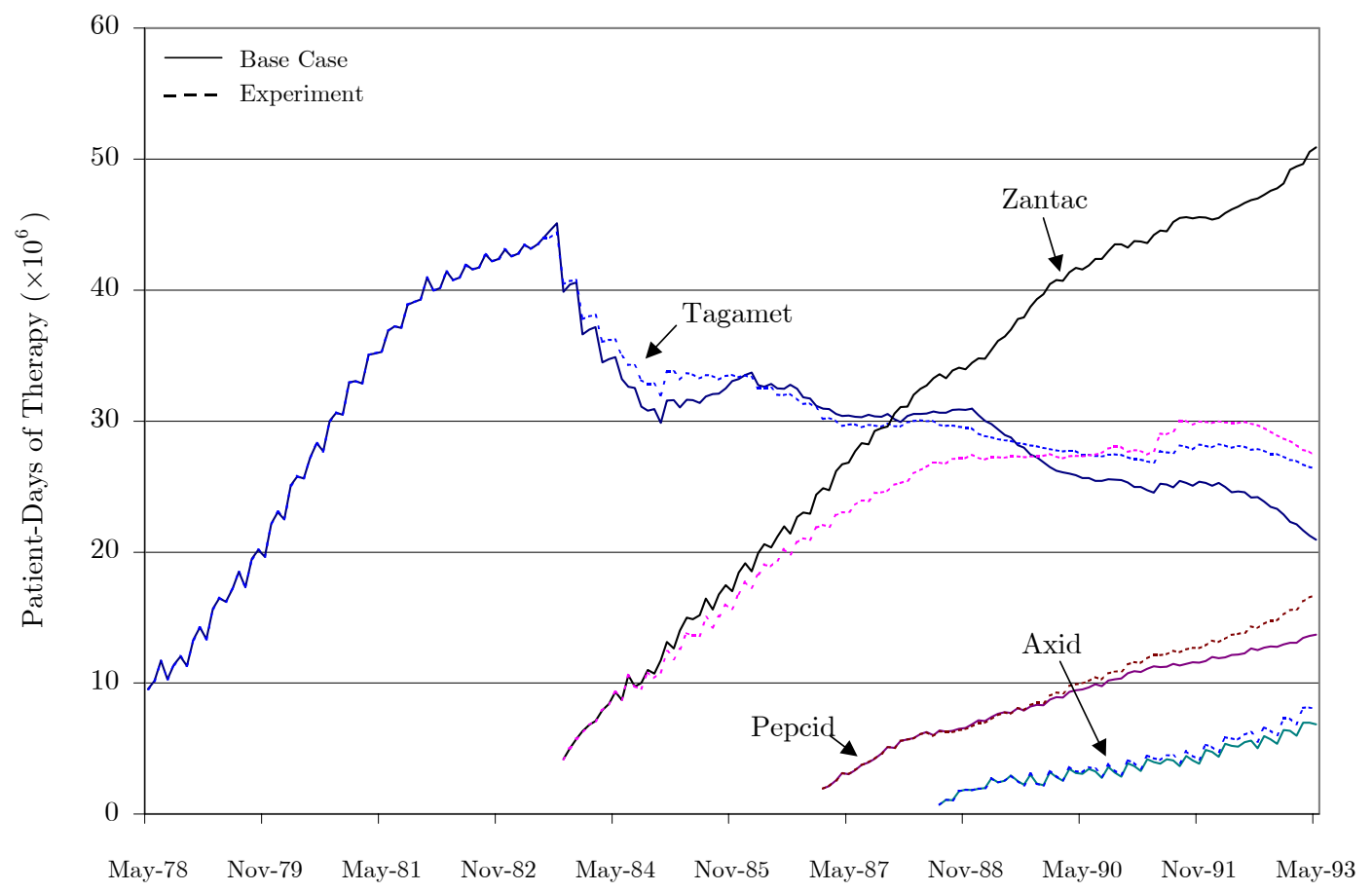

Figure 11: Zantac Detailing and Attributes Set Equal to Tagamet's

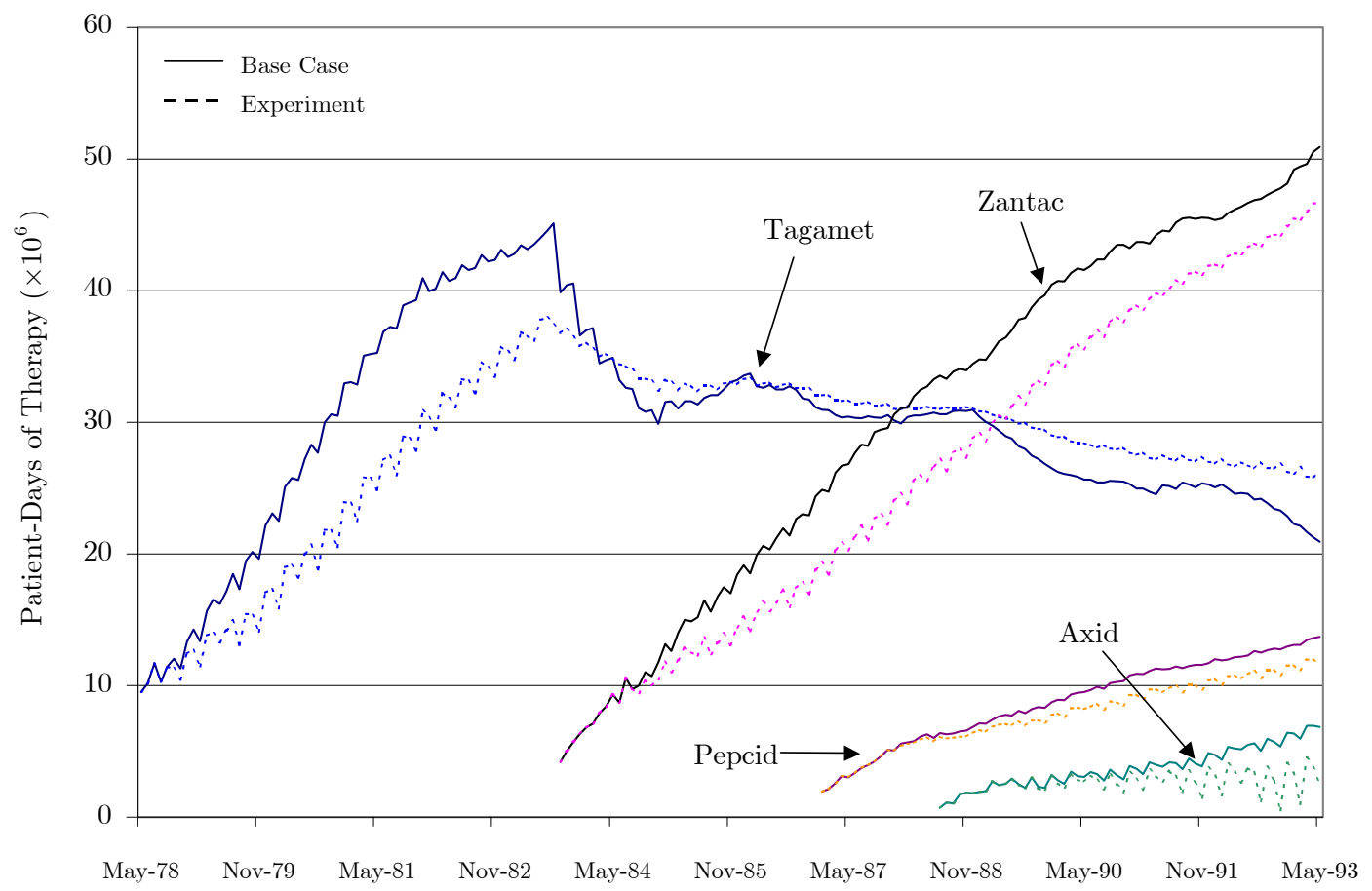

Figure 12: Coefficient $d_{1}$ Set Equal to 50 Percent of Estimated Value 